\title{
Characteristics of surface wind structure of tropical cyclones over the north Indian Ocean
}

\author{
M Mohapatra* and Monica Sharma \\ India Meteorological Department, Mausam Bhavan, Lodi Road, New Delhi 110 003, India. \\ ${ }^{*}$ Corresponding author.e-mail: mohapatraimd@gmail.com
}

Tropical cyclone (TC) wind field monitoring and forecast are important for mariners, ships on sea and modelling group for creation of synthetic vortex, and storm surge and coastal inundation forecasting. Among others, a multi-platform satellite surface wind analysis developed by Co-operative Institute for Research in the Atmosphere (CIRA), USA for the TCs are referred by India Meteorological Department for surface wind field monitoring of TC. Hence, a study has been undertaken to analyze the characteristics of surface wind distribution and hence the structure of TC based on the real time data available from CIRA during 2007-2013. The study includes 19 TCs over the Bay of Bengal (BOB) and six over Arabian Sea (AS). The maximum radial extent of winds reaching threshold values of 34(17), 50(26) and 64(33) knot $\left(\mathrm{ms}^{-1}\right)$ in each of the four geographical quadrants has been segregated with respect to season of formation, basin of formation and intensity of TC for analysis. The objective is to develop a reference surface wind structure of TC and examine its validity with respect to physical processes.

The size of outer core $\left(34(17)\right.$ knot $\left(\mathrm{ms}^{-1}\right)$ wind radial extension) as well as inner core $(50(26)$ and 64(33) knot $\left(\mathrm{ms}^{-1}\right)$ wind radial extension) increases significantly with increase in intensification of TC over BOB during both pre-monsoon and post-monsoon seasons and over AS during pre-monsoon season. The outer core of winds in TCs over the BOB is asymmetric in both pre-monsoon and post-monsoon seasons and for all categories of intensity of TCs. On the other hand, the asymmetry in inner core winds is significantly less. There is also no asymmetry in radial wind extension over the AS during both the seasons, except in case of outer core wind radial extension of VSCS during pre-monsoon season. The low level environment like enhanced cross equatorial flow, lower/middle level relative humidity, vertical wind shear and proximity of TC to the land surface are the determining factors for the size and asymmetry of TCs over the NIO.

\section{Introduction}

As the government, industry and private sector information needs become more sophisticated and the observational data improve, there is an increasing need for reliable tropical cyclone (TC) surface wind analysis (Knaff et al. 2011). There is also now clear evidence that TC impacts (wind and storm surge damage) are related to measures of the kinetic energy derived from the surface wind structures.
Disaster managers who prepare for the impact of a landfalling TC may use the wind field information as guidance as to where the most severe wind or surge damage may occur. On the other hand, an insurer may want quantitative damage estimates. In this case, surface wind structure, even in a quadrant-based form can serve the purpose. In quadrant-based form, the "wind radii' products represent the estimated maximum horizontal extent of a particular maximum

Keywords. Tropical cyclone; surface wind radii; north Indian Ocean. 
sustained wind speed (MSW), viz., 34(17), 50(26) and $64(33)$ knot $\left(\mathrm{ms}^{-1}\right)$ from the circulation centre (referred as R34, R50 and R64) in each of four quadrants, viz., northeast (NE), southeast (SE), northwest (NW) and southwest (SW). This quadrant-based wind information also serves as input to numerical weather prediction (NWP) models and storm surge models that are run prior to landfalling events to create synthetic vortex (Chourasia et al. 2013), as most of the NWP models fail to simulate accurately the location and intensity of the TC. The creation of synthetic vortex helps in improving the track and intensity forecast of the model. In the parametric storm surge prediction models, the surface wind structure in the quadrantbased form along with the radius of maximum wind (RMW) and pressure drop at the centre are utilized to create the wind stress and hence predict the storm surge (Dube et al. 2013). In post-event cases, these wind structure data are utilized for diagnosis of TC and to better plan future TC forecasts. Engineers and planners rely on historical TC information to determine long-term risks to facilities and infrastructure and to ensure the resilience of communities to potential disasters.

Considering all the above, TC surface wind fields are the subject of operational products of various TC forecasting agencies in the globe. There have been several attempts in recent years to generate real time surface wind distribution around the centre of TC through satellite-based observations (Kossin et al. 2007), as actual observations through ships and buoys are very meager over the vast Oceanic regions, especially over north Indian Ocean (Mohapatra et al. 2012) and the observations through aircraft reconnaissance using various instrumentation including drop-sonde, etc., are mostly limited to north Atlantic Ocean with the initiative of USA. For this purpose, Co-operative Institute for Research in the Atmosphere (CIRA), USA combines several satellitebased inputs from scatterometer, cloud motion vectors, IR flight-level proxy winds and AMSU-based non-linear balance winds (Bessho et al. 2006) to create global satellite-only surface wind analysis. The method makes use of a variational data fitting technique on a cylindrical grid that allows variable data weights in combination with bulk quality control (Knaff et al. 2007). Since 1996, wind analyses ( $\mathrm{H}^{*}$ Wind) have been conducted on a research basis by Hurricane Research Division (HRD), National Ocean and Atmospheric Administration (NOAA), USA to create real-time hurricane wind field guidance for forecasters at the National Hurricane Center (NHC), USA. Verification of the wind fields from CIRA against $\mathrm{H}^{*}$ Wind analyses shows that the resulting wind field has mean absolute errors that are generally $<5 \mathrm{~m} / \mathrm{s}$. Results were also shown to out-perform Atlantic climatology for 34(17), 50(26) and 64(33) knot $\left(\mathrm{ms}^{-1}\right)$ wind radii estimates as well as show significant temporal correlation with TC size changes (Knaff et al. 2011). It is found that wind radii are well correlated with storm radii. Errors are generally lower than climatology (Knaff et al. 2007), except in the SE quadrant. However, $64(33)$ knot $\left(\mathrm{ms}^{-1}\right)$ winds are too large, which causes central pressure estimates to be too low for the most intense systems. The 34(17) knot $\left(\mathrm{ms}^{-1}\right)$ winds are a little too small. There are negative biases in SE (NE) quadrant in the Northern Hemisphere (Southern Hemisphere). Most of the inner core errors are associated with poorly estimated RMWs.

The TC surface wind structure monitoring and forecast was commenced by IMD in 2010 (Regional Specialized Meteorological Centre (RSMC), New Delhi, 2011) with the very severe cyclonic storm (VSCS), Giri (20-22 October, 2010) over the Bay of Bengal (BOB). This operational product contained analyzed and forecast wind field (wind radii in four geographical quadrants, viz., NW, NE, SW and SE for thresholds of 28(14), 34(17), 50(26) and 64(33) knots $\left(\mathrm{ms}^{-1}\right)$ ) valid for next $72 \mathrm{hr}$ till 2012 and forecast period was extended to $120 \mathrm{hr}$ from 2013. The primary methods for TC wind field estimation by IMD involves satellite-based scatterometer estimates, cloud motion vectors, water vapour-based wind vectors, wind estimates from brightness temperatures, estimates from Radar products and NWP model analyses products (IMD 2013). The multiplatform satellite-based surface wind analyses as developed by CIRA for the TCs on real time basis are also utilized by IMD for monitoring of surface wind radii in four geographical quadrants of TCs. Detailed review of the status of monitoring and prediction of surface wind structure in the globe and in India are discussed in section 2 . In the absence of aircraft reconnaissance and limited buoys, satellitebased wind observations are the only source when TC is located in the deep sea region of NIO. Hence, the effective utilization of above-mentioned multiplatform-based satellite-derived wind product is very essential to minimize the error in intensity and structure monitoring and forecast. So, a study has been undertaken to analyze the mean characteristics of surface wind distribution and hence the structure of TC based on the real time data available from CIRA during 2007-2013. The database contains 25 TCs over the NIO as defined by RSMC, New Delhi. It includes 19 TCs over the BOB and 6 TCs over the Arabian Sea (AS). The objective is to examine this product with respect to physical processes over the region in addition to deriving the climatological information. This study can be utilized as a reference for (i) validation of NWP model analyses and forecasts and (ii) real time monitoring and forecast of surface wind structure. Further, it can be utilized for better understanding 
of physical processes in genesis, intensification and movement of TCs over the NIO.

\section{Status of surface wind structure monitoring and prediction in India and the globe}

Over the north Atlantic Ocean, the technology of observing the surface wind from reconnaissance aircraft has greatly improved with the operational implementation of stepped frequency microwave radiometer (SFMR) on reconnaissance aircraft utilized both at NOAA for research and NHC for routine operational reconnaissance (Uhlhorn et al. 2007). The use of the SFMR and scatterometrybased sea surface wind data and flight-level data are used to analyze TC wind field size and structure. However, most of the other TC warning centres rely on satellite techniques to assess $\mathrm{TC}$ winds and structure due to lack of aircraft reconnaissance and several new techniques have been developed in the recent years for this purpose.

Wind radii for $34(17)$ and $50(26)$ knot $\left(\mathrm{ms}^{-1}\right)$ are forecast through $72 \mathrm{hr}$ and 64(33) knot $\left(\mathrm{ms}^{-1}\right)$ radii are forecast through $36 \mathrm{hr}$ by NHC, USA (Rappaport et al. 2009). While this representation of the surface wind structure is recognized as being crude, NHC believes that insufficient observations are available to accurately specify the analysis (or forecast) wind field to any greater precision. Even when reconnaissance aircraft data are available, the vast majority of the circulation remains unsampled. Even best-track (Jarvinen et al. 1988) estimates of TC size are considered by forecasters to have large relative errors (perhaps $25-40 \%$ ).

Since 2007, JMA has used ASCAT data for $30(15)$ and 50(26) knot $\left(\mathrm{ms}^{-1}\right)$ wind radii determination of tropical storms (TCs with MSW of 34(17) knot $\left(\mathrm{ms}^{-1}\right)$ or more). Rain flagged and wind speed estimates greater than 50(26) knot $\left(\mathrm{ms}^{-1}\right)$ are not utilized in such analyses. In RSMC, La Reunion, scatterometry is also interpreted with caution in the 40(21)-50(26) knot $\left(\mathrm{ms}^{-1}\right)$ range, and considered lowbiased near the RMW (Uhlhorn and Black 2003). The available sparse surface observations from buoys or synoptic stations (ships are used with more caution) are used to check validity of scatterometer winds. Winds radii are given by quadrants for 30(15) knot $\left(\mathrm{ms}^{-1}\right)$ and 50(26) knot $\left(\mathrm{ms}^{-1}\right)$. No wind radii and RMW forecasts are made by RSMC La Re Union. The Australian Bureau of Meteorology (BoM) has three Tropical Cyclone Warning Centres (TCWCs) in Brisbane, Darwin and Perth. The radii of 34(17), 50(26) and 64(33) knot $\left(\mathrm{ms}^{-1}\right)$ winds are analyzed by these centres based on knowledge of climatology, ASCAT, ship observations of opportunity, and the extent/nature of convection, especially as measured by satellite (passive microwave). The CIRA/NESDIS wind analyses are also used by them, although forecasters find the values obtained are typically larger than in-house estimates. The BoM TCWCs forecast wind radii using a combination of persistence with a bias towards climatology and stage of development; considering both landfall and model surface wind fields.

RSMC, New Delhi analyses radii of 28(14), $34(17), 50(26)$ and $64(33)$ knot $\left(\mathrm{ms}^{-1}\right) 3$-min winds in four geographical quadrants every $6 \mathrm{hr}$ based on 00, 06, 12 and 18 UTC from the stage of deep depression (MSW of 28(14) knot $\left(\mathrm{ms}^{-1}\right.$ ) or more) onwards, if the system is expected to intensify into a TC. In addition, the forecast wind radii of $28(14)$, 34(17), 50(26) and 64(33) knot $\left(\mathrm{ms}^{-1}\right)$ threshold are generated up to $120 \mathrm{hr}$ in the interval of $6 \mathrm{hr}$ for first 24-hr forecast period and in the interval of $12 \mathrm{hr}$ for the subsequent forecast periods. The primary methods for TC wind field estimation by IMD involve satellite-based scatterometer estimates, cloud motion vectors, water vapour-based wind vectors, wind estimates from brightness temperatures, multi-platform satellite-based wind developed by CIRA, estimates from RADAR products and NWP model analyses and forecast products (IMD 2013). The IMD's NWP model system guidance includes IMD-Global Forecast system (GFS), UK Meteorogical Office, Japan Meteorological Agency (JMA), ARP-Meteo-France, National Centre for Environmental Prediction (NCEP) GFS, Weather Research and Forecast (WRF) and Hurricane WRF models. Consensus analysis and forecasts that gather all or part of the numerical forecast and uses synoptic and climatological guidance are utilized to issue analysis and forecast surface wind radii in four geographical quadrants.

\section{Data and methodology}

A study has been undertaken to analyze the mean characteristics of surface wind distribution and hence the structure of TC based on the real time multi-platform satellite-based data available from CIRA. Details about the CIRA data are discussed in section 3.1. To carry out the study, the TC data from 2007-2013 over the NIO has been considered. The maximum radial extent of winds reaching threshold values of 34(17), 50(26) and 64(33) knot $\left(\mathrm{ms}^{-1}\right)$ in each of the four geographical quadrants has been segregated with respect to season, basin and intensity. The mean and standard deviation (SD) for each set of data are calculated and analyzed.

The NIO consists of two sub-basins, viz., BOB and AS. As the physical characteristics with genesis, intensification and movement of TCs over the 
AS differ from that of BOB, the surface wind structure has been analyzed with respect to BOB and AS separately. There are 25 TCs over the NIO including 19 TCs over the BOB and 6 over the AS during the period. A total of 404 cases based on 00, 06, 12 and 18 UTC data of CIRA are considered. Further, the TCs over the NIO show bi-modal behaviour (IMD 2008) in their genesis with primary maxima in post-monsoon season (OctoberDecember) and secondary maxima in pre-monsoon season (March-May). The surface wind analysis has been performed during these two seasons separately, as their tracks, genesis and intensification characteristics are different in these two different seasons. There has been one TC during monsoon months (1-7 June 2007). Since the TC in the month of June (onset phase of monsoon) has premonsoon characteristics, it has been considered as the TC in pre-monsoon season (March-May) for analysis purpose. As such, there are 9 (6 over BOB and 3 over $\mathrm{AS}$ ) and 16 (13 over $\mathrm{BOB}$ and 3 over AS) TCs during pre-monsoon and post-monsoon seasons respectively (table 1 , figure 1).
To verify the impact of intensity of TCs on the surface wind structure, the TCs have been classified into four categories, viz., (i) cyclonic storm (CS) (maximum surface wind speed of 34(17)-47(24) knot $\left.\left(\mathrm{ms}^{-1}\right)\right)$, (ii) severe cyclonic storm (SCS) (48(25)$63(32)$ knot $\left(\mathrm{ms}^{-1}\right.$ ) or more), (iii) very severe cyclonic storm (VSCS) (64(33)-119(61) knot $\left(\mathrm{ms}^{-1}\right)$ ) and (iv) super cyclonic storm (SuCS) $\left(120(62)\right.$ knot $\left(\mathrm{ms}^{-1}\right)$ or more) based on the MSW estimated by CIRA surface wind analysis. The definition of the TCs analyzed here is same as that adopted by IMD (2013).

Past studies indicate that relative humidity $(\mathrm{RH})$ and vertical wind shear of horizontal wind play dominant role in determining surface wind structure of TC (Hill and Lackmann 2009; Xu and Wang 2010). To analyze the associated relative humidity $(\mathrm{RH})$, we have considered the horizontal and vertical profile of $\mathrm{RH}$ around the TC centre based on NCEP/NCAR Reanalysis-2 (Kanamitsu et al. 2002). This is a $1^{\circ} \times 1^{\circ}$ gridded point data at six hourly interval (00, 06, 12 and 18 UTC) corresponding to the time of observation of sea surface wind based on multi-platform dataset available from CIRA.

Table 1. Details of the tropical cyclones (TCs) under consideration.

\begin{tabular}{|c|c|c|c|c|c|c|c|}
\hline Sl. no. & Year & Life period & $\begin{array}{c}\text { Maximum } \\
\text { intensity }\end{array}$ & $\begin{array}{c}\text { Basin of } \\
\text { formation }\end{array}$ & $\begin{array}{l}\text { Season of } \\
\text { formation }\end{array}$ & $\begin{array}{c}\text { Type of track } \\
\text { of TC }\end{array}$ & $\begin{array}{c}\text { Region of } \\
\text { landfall }\end{array}$ \\
\hline 1 & 2007 & 13-15 May & CS & $\mathrm{BOB}$ & $\mathrm{PM}$ & $\mathrm{S} / \mathrm{C}$ & Bangladesh \\
\hline 2 & 2007 & 1-7 June & $\mathrm{SuCS}$ & AS & Monsoon & $\mathrm{S} / \mathrm{C}$ & Oman, Iran \\
\hline 3 & 2007 & 11-16 November & VSCS & $\mathrm{BOB}$ & PS & $\mathrm{R}$ & Bangladesh \\
\hline 4 & 2008 & 27 April -3 May & VSCS & $\mathrm{BOB}$ & $\mathrm{PM}$ & $\mathrm{R}$ & Myanmar \\
\hline 5 & 2008 & 25-27 October & $\mathrm{CS}$ & $\mathrm{BOB}$ & PS & $\mathrm{S} / \mathrm{C}$ & Bangladesh \\
\hline 6 & 2008 & 13-16 November & $\mathrm{CS}$ & $\mathrm{BOB}$ & PS & $\mathrm{S} / \mathrm{C}$ & $\mathrm{AP}$ \\
\hline 7 & 2008 & 25-27 November & CS & $\mathrm{BOB}$ & PS & $\mathrm{S} / \mathrm{C}$ & $\mathrm{TN}$ \\
\hline 8 & 2009 & 14-17 April & CS & $\mathrm{BOB}$ & $\mathrm{PM}$ & $\mathrm{R}$ & Bangladesh \\
\hline 9 & 2009 & 23-26 May & SCS & $\mathrm{BOB}$ & $\mathrm{PM}$ & $\mathrm{S} / \mathrm{C}$ & WB \\
\hline 10 & 2009 & 9-12 November & $\mathrm{CS}$ & AS & PS & $\mathrm{R}$ & Maharashtra \\
\hline 11 & 2009 & 10-15 December & CS & $\mathrm{BOB}$ & PS & $\mathrm{R}$ & Sri Lanka \\
\hline 12 & 2010 & 17-21 May & SCS & $\mathrm{BOB}$ & $\mathrm{PM}$ & $\mathrm{R}$ & $\mathrm{AP}$ \\
\hline 13 & 2010 & 19-23 May & CS & AS & $\mathrm{PM}$ & $\mathrm{S} / \mathrm{C}$ & - \\
\hline 14 & 2010 & 31 May-7 June & VSCS & $\mathrm{AS}$ & $\mathrm{PM}$ & $\mathrm{R}$ & Oman, Pakistan \\
\hline 15 & 2010 & 20-23 October & VSCS & $\mathrm{BOB}$ & PS & $\mathrm{S} / \mathrm{C}$ & Myanmar \\
\hline 16 & 2010 & 4-8 November & SCS & $\mathrm{BOB}$ & PS & $\mathrm{S} / \mathrm{C}$ & $\mathrm{TN}$ \\
\hline 17 & 2011 & 29 October -4 November & $\mathrm{CS}$ & AS & PS & $\mathrm{R}$ & Oman \\
\hline 18 & 2011 & 25-31 December & VSCS & $\mathrm{BOB}$ & PS & $\mathrm{S} / \mathrm{C}$ & $\mathrm{TN}$ \\
\hline 19 & 2012 & 28 October-1 November & $\mathrm{CS}$ & $\mathrm{BOB}$ & PS & $\mathrm{R}$ & $\mathrm{TN}$ \\
\hline 20 & 2012 & 22-26 October & CS & $\mathrm{AS}$ & PS & $\mathrm{S} / \mathrm{C}$ & Somalia \\
\hline 21 & 2013 & 10-16 May & $\mathrm{CS}$ & $\mathrm{BOB}$ & $\mathrm{PM}$ & $\mathrm{R}$ & Bangladesh \\
\hline 22 & 2013 & 8-14 October & VSCS & $\mathrm{BOB}$ & PS & $\mathrm{S} / \mathrm{C}$ & Odisha \\
\hline 23 & 2013 & 19-22 November & SCS & $\mathrm{BOB}$ & PS & $\mathrm{S} / \mathrm{C}$ & $\mathrm{AP}$ \\
\hline 24 & 2013 & 23-28 November & VSCS & $\mathrm{BOB}$ & PS & $\mathrm{S} / \mathrm{C}$ & $\mathrm{AP}$ \\
\hline 25 & 2013 & 6-14 December & VSCS & $\mathrm{BOB}$ & PS & $\mathrm{R}$ & $\mathrm{TN}$ \\
\hline
\end{tabular}

CS: cyclonic storm, SCS: severe cyclonic storm, VSCS: very severe cyclonic storm.

BOB: Bay of Bengal, AS: Arabian Sea, PM: pre-monsoon season, PS: post-monsoon season.

R: recurving/looping, S/C: straight moving/climatological.

AP: Andhra Pradesh, TN: Tamil Nadu and Puducherry. 


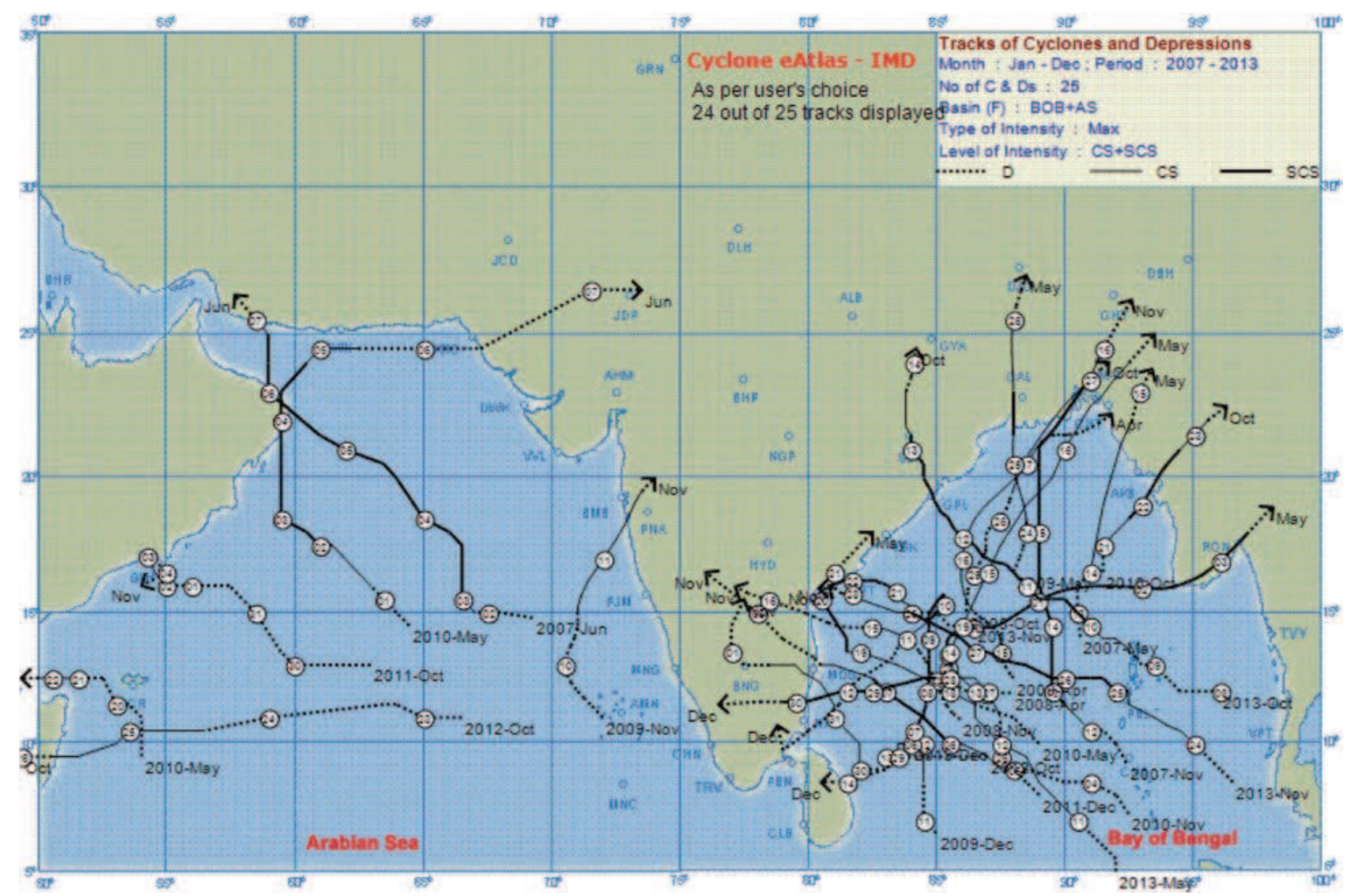

Figure 1. Tracks of TCs over the north Indian Ocean during 2007-2013 under consideration in the study.

Vertical profile has been considered for the standard isobaric levels from $1000-100 \mathrm{hPa}$ at four representative points located $2^{\circ}$ latitude/longitude away from the centre of the TC in four geographical quadrants. As the mid-tropospheric $\mathrm{RH}$ plays a significant role in cyclogenesis and intensification, the horizontal distribution of $\mathrm{RH}$ at $500 \mathrm{hPa}$ level is also presented and analyzed. Quality of this dataset depends on the observations available over the sea region and their assimilation in the NCEP Global Forecast System (GFS) model. The vertical wind shear between upper and lower tropospheric levels has also been analyzed based on the satellitederived products available from Co-operative Institute for Meteorological Satellite Studies (CIMSS) (http://tropic.ssec.wisc.edu) corresponding to the time of observation of surface wind from multiplatform satellite dataset from CIRA. The limitation of this data includes the fact that, this product is based on tracking of the cloud or water vapour features as mentioned above and low level winds are often not available near the core of TC. Hence, the method of bogusing is applied using ECMWF analyses and forecasts as first guess.

Though there can be other dynamical factors like lower level vorticity/convergence and upper level divergence, etc., governing the wind structure of TC, here the study has been limited to analysis of the role of $\mathrm{RH}$ and vertical wind shear. The role of other dynamical features will be taken up in a separate study.

\subsection{Surface wind data developed by CIRA}

The experimental global product by CIRA that combine satellite-based winds consists of (i) advanced microwave sounding unit (AMSU)-derived balanced winds, (ii) scatterometry, (iii) cloud/feature track winds, and (iv) infra red (IR)-based analogs of flight-level (850-700 hPa) winds (i.e., aircraftbased wind analogs). These are created as part of an NCEP, USA operational TC intensity and structure products. The real-time cases are available at http://rammb.cira.colostate.edu/products / tc_realtime/ and http://www.ssd.noaa.gov/PS/ TROP/mtcswa.html.

AMSU antenna temperatures are used to estimate temperature retrievals and cloud liquid water (Goldberg 1999). Cloud liquid water and horizontal temperature anomalies are used to correct temperature retrievals (Demuth et al. 2004, 2006). The corrected temperatures are then analyzed on standard pressure levels (using GFS boundary conditions). Using the resulting height field, the nonlinear balance equation is solved to estimate the 
2-dimensional wind field at $700 \mathrm{hPa}$ level, which is then converted into 10-m surface wind (Bessho et al. 2006). Because of the resolution of AMSU, the winds in the core of TCs are not resolved using this method. The AMSU is based on Polar orbiting satellite (NOAA-15, 16 and 18), which has poor resolution. The winds are too weak near the centre and too asymmetric.

Sea surface wind based on principle of scatterometry uses active radar method (k-band, c-band). The surface wind (10-m wind) vectors are derived from ASCAT and OSCAT scatterometers. While ASCAT uses c-band radar with $25 \mathrm{~km}$ resolution and less affected by precipitation, OSCAT, like QuikSCAT uses k-band radar. They provide accurate low level winds and attenuate in high winds (i.e., $\left.\lesssim 50(26) \operatorname{knot}\left(\mathrm{ms}^{-1}\right)\right)$. Winds are adversely affected by heavy precipitation (Uhlhorn and Black 2003).

The cloud/feature tracked winds are routinely available based on Geostationary Operational Environmental Satellites (GOES), USA. However, low-level winds are often not available near the core of TCs. It is based on tracking of clouds or water vapor features, which are assigned a pressure level. These winds are available once in $3 \mathrm{hrs}$.

The IR flight-level analog winds (Mueller et al. 2006) are representative winds near the core of the TC and make surface analysis possible. Based on IR imagery, the analysis of the azimuthal mean brightness temperatures is carried out, which helps in scaling the TC size by providing two-dimensional flight-level $(700 \mathrm{hPa})$ wind estimate. The shortcomings are that the winds are too symmetric and have limitations in cases of small RMW and multiple wind maxima.

\section{Results and discussion}

The mean pattern of surface wind radii for wind threshold of 34(17), 50(26) and 64(33) knot $\left(\mathrm{ms}^{-1}\right)$ with respect to AS TCs during pre-monsoon and post-monsoon seasons are analysed and discussed in sections 4.1 and 4.2, respectively. Similarly, mean pattern of surface wind radii for wind threshold of 34(17), 50(26) and 64(33) knot $\left(\mathrm{ms}^{-1}\right)$ with respect to BOB TCs during pre-monsoon and postmonsoon seasons are presented and discussed in sections 4.3 and 4.4 , respectively.

\subsection{Mean pattern of surface wind radii of TCs over the AS during pre-monsoon season}

The mean pattern of surface wind radii for four geographical quadrants of TCs over the AS during pre-monsoon season with different intensities are shown along with the SD in table 2 and figure 2. The results have been analyzed with respect to asymmetry in wind and size of the $\mathrm{TC}$ in the following subsections.

\subsubsection{Asymmetry in wind distribution}

Considering 34(17) knot $\left(\mathrm{ms}^{-1}\right)$ wind threshold, radius varies from 40(74) nautical mile $(\mathrm{nm})(\mathrm{km})$ in NW and SW quadrants to $45(83) \mathrm{nm}(\mathrm{km})$ in $\mathrm{NE}$ and $48(89) \mathrm{nm}(\mathrm{km})$ in SE quadrant in case of CS (table 2, figure 2). There is no significant difference in mean wind radii in four geographical quadrants according to Student's $t$ test (table 3 ). Hence, the wind distribution is symmetric around the centre. When the TC intensifies into SCS,

Table 2. Mean wind radii $(\mathrm{nm} / \mathrm{km})$ in four quadrants of a tropical cyclone over the Arabian Sea during pre-monsoon season.

\begin{tabular}{|c|c|c|c|c|c|c|c|c|c|c|c|}
\hline \multirow{2}{*}{$\begin{array}{l}\text { Wind } \\
\text { threshold } \\
(\mathrm{knot} / \\
\left.\mathrm{ms}^{-1}\right) \\
\end{array}$} & \multirow[b]{2}{*}{ Category } & \multicolumn{5}{|c|}{ Mean wind radii $(\mathrm{nm} / \mathrm{km})$} & \multicolumn{5}{|c|}{ Standard deviation $(\mathrm{nm} / \mathrm{km})$} \\
\hline & & NW & $\mathrm{NE}$ & SW & $\mathrm{SE}$ & Mean & NW & $\mathrm{NE}$ & SW & $\mathrm{SE}$ & Mean \\
\hline \multirow[t]{4}{*}{$34 / 17$} & $\mathrm{CS}$ & $40 / 74(15)$ & $45 / 83(16)$ & $40 / 74(16)$ & $48 / 89(17)$ & $43 / 80$ & $13 / 24$ & $16 / 30$ & $10 / 19$ & $17 / 31$ & $13.6 / 25.2$ \\
\hline & SCS & $76 / 141(14)$ & $72 / 133(14)$ & $71 / 131(14)$ & $71 / 131(14)$ & $72.4 / 134.1$ & $19 / 35$ & $16 / 30$ & $17 / 31$ & $21 / 39$ & $17.2 / 31.9$ \\
\hline & VSCS & $122 / 226(17)$ & $134 / 248(17)$ & $107 / 198(17)$ & $117 / 217(17)$ & $120 / 222$ & $18 / 33$ & $30 / 56$ & $27 / 50$ & $44 / 81$ & $22.8 / 42$ \\
\hline & $\mathrm{SuCS}$ & $113 / 209(5)$ & $127 / 235(5)$ & $120 / 222(5)$ & $122 / 226(5)$ & $120 / 223$ & $27 / 50$ & $40 / 74$ & $12 / 22$ & $17 / 31$ & $18.4 / 34.1$ \\
\hline \multirow[t]{3}{*}{$50 / 26$} & SCS & $40 / 74(14)$ & $40 / 74(14)$ & $40 / 74(12)$ & $41 / 76(13)$ & $40.3 / 74.6$ & $11 / 20$ & $12 / 22$ & $11 / 20$ & $14 / 26$ & $12.0 / 22.2$ \\
\hline & VSCS & $69 / 128(17)$ & $71 / 131(17)$ & $62 / 115(17)$ & $61 / 113(17)$ & $65.8 / 122$ & $26 / 48$ & $20 / 37$ & $22 / 41$ & $10 / 19$ & $18.4 / 34.1$ \\
\hline & $\mathrm{SuCS}$ & $72 / 133(5)$ & $70 / 130(5)$ & $65 / 120(5)$ & $65 / 120(5)$ & $68.0 / 126$ & $21 / 39$ & $17 / 31$ & $14 / 26$ & $7 / 13$ & $13.0 / 24$ \\
\hline \multirow[t]{2}{*}{$64 / 33$} & VSCS & $40 / 74(17)$ & $43 / 80(17)$ & $39 / 72(15)$ & $41 / 76(15)$ & $40.8 / 75.6$ & $16 / 30$ & $13 / 24$ & $12 / 22$ & $11 / 20$ & $12.6 / 23.3$ \\
\hline & $\mathrm{SuCS}$ & $44 / 81(5)$ & $46 / 85(5)$ & $40 / 74(5)$ & $44 / 81(5)$ & $43.7 / 90$ & $12 / 22$ & $11 / 20$ & $10 / 19$ & $11 / 20$ & $10.8 / 20$ \\
\hline
\end{tabular}

CS: cyclonic storm, SCS: severe CS, VSCS: very severe CS, SuCS: super CS.

NW: northwest, NE: northeast, SW: southwest, SE: southeast.

Figures inside the parentheses indicate number of observations. 

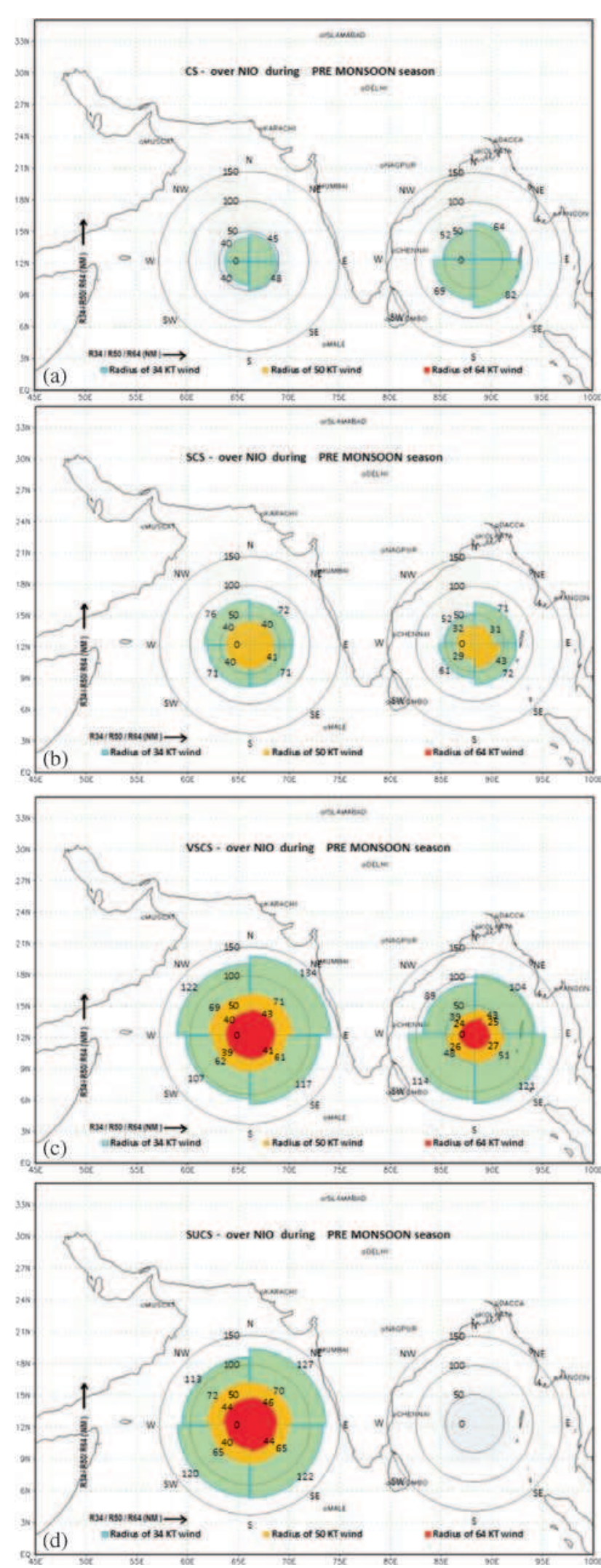

Figure 2. Quadrant radii of 34(17) (green), 50(26) (yellow) and 64(33) (red) knot $\left(\mathrm{ms}^{-1}\right)$ wind (R34, R50 and R64) in association with TCs of different intensities (a) CS, (b) SCS, (c) VSCS, and (d) SuCS during pre-monsoon season. The values written inside each quadrant indicate mean R34, R50 and R64 (nm). wind radius of $34(17)$ knot $\left(\mathrm{ms}^{-1}\right)$ wind becomes 71(131) nm (km) in SE and SW quadrants, 72(133) $\mathrm{nm}(\mathrm{km})$ in NE and 76(141) $\mathrm{nm}(\mathrm{km})$ in NW quadrants (table 2). Like the case of CS, the difference in mean wind radii is not statistically significant for any two geographical quadrants (table 3). When SCS intensifies into VSCS stage, the radial extent becomes maximum in NE quadrant $(134(248) \mathrm{nm}(\mathrm{km}))$ followed by NW quadrant $(122(226) \mathrm{nm}(\mathrm{km}))$ and is minimum in SW quadrant $(107(198) \mathrm{nm}(\mathrm{km}))$. The difference in mean wind radii between NW and SW quadrants is significant at $5 \%$ level and between NE and SW quadrants at $1 \%$ level (table 3 ). When the system intensifies from VSCS to SuCS stage, there is no significant change in asymmetry of the wind distribution. However, the number of cases in SuCS stage is less (5) to generalize the conclusion. Considering the radius of 50(26) knot $\left(\mathrm{ms}^{-1}\right)$ wind threshold, the asymmetry decreases in case of SCS, VSCS and SuCS and is statistically insignificant (tables 2, 3, figure $2)$. The asymmetry further decreases when we consider wind radii of $64(33)$ knot $\left(\mathrm{ms}^{-1}\right)$ wind threshold and distribution becomes almost uniform around the centre. Thus the asymmetry is limited to the outer core of the storm, which determines the size of the storm and in case of VSCS only with the extent of 34(17) knot $\left(\mathrm{ms}^{-1}\right)$ wind being maximum in northeastern sector. The higher wind in northeastern sector may be due to addition of storm vector motion in this sector, as the storm moves west-northwestwards/northwestwards (figure 1). To analyze the cause and effect relationship between the storm vector motion and the wind radii distribution, the translational speed and direction on each day of the TC have been calculated and compared with the wind radii. Considering the example of VSCS, Phet over AS on 3 June 2010 when the intensity was VSCS, the mean translational speed and direction of the TC was 5.2(2.7) $\operatorname{knot}\left(\mathrm{ms}^{-1}\right)$ and $300^{\circ}$, respectively. From figure 3(c), winds in northeast sector are east-southeasterly and hence the storm motion vector becomes additive, whereas it does not have much effect on southeast sector and reduces the wind in northwest and southwest sectors. The maximum impact of storm motion vector in modifying the wind distribution is about $5(2.6)$ knot $\left(\mathrm{ms}^{-1}\right)$. However, as it can be seen from figure $3(\mathrm{a}-\mathrm{f})$, the R-34 is not always maximum in NE quadrant throughout the life period of $\mathrm{TC}$, as it becomes higher in SE quadrant on some days. Koteswaram and Gaspar (1956) analyzing the surface wind structure based on the ship data of severe cyclones (48(25) knot $\left(\mathrm{ms}^{-1}\right)$ and more) over the BOB and AS during 1925-1954 have shown that wind velocity is more in the right half of the TC with respect to direction of movement. The asymmetry in maximum wind varied from right forward 
Table 3. Level of significance (\%) in difference of mean wind radii $(\mathrm{nm} / \mathrm{km})$ in four geographical quadrants of tropical cyclones over the Bay of Bengal and Arabian Sea.

\begin{tabular}{|c|c|c|c|c|c|c|c|c|c|c|c|c|c|c|}
\hline \multirow{3}{*}{$\begin{array}{l}\text { Wind } \\
\text { threshold } \\
\left(\mathrm{knot} / \mathrm{ms}^{-1}\right)\end{array}$} & \multirow[b]{3}{*}{ Season } & \multirow[b]{3}{*}{ Category } & \multicolumn{12}{|c|}{ Level of significance (\%) in difference of mean wind radii between various quadrants } \\
\hline & & & $\begin{array}{l}\text { NW- } \\
\mathrm{NE}\end{array}$ & $\begin{array}{c}\mathrm{NW}_{-} \\
\mathrm{SW}\end{array}$ & $\begin{array}{c}\text { NW } \\
\text { SE } \\
\end{array}$ & $\begin{array}{l}\mathrm{NE}_{-} \\
\mathrm{SW}\end{array}$ & $\begin{array}{c}\mathrm{NE}- \\
\mathrm{SE} \\
\end{array}$ & $\begin{array}{c}\mathrm{SW}- \\
\mathrm{SE} \\
\end{array}$ & $\begin{array}{c}\mathrm{NW}- \\
\mathrm{NE} \\
\end{array}$ & $\begin{array}{c}\mathrm{NW}_{-} \\
\mathrm{SW}\end{array}$ & $\begin{array}{c}\text { NW- } \\
\text { SE }\end{array}$ & $\begin{array}{l}\mathrm{NE}- \\
\mathrm{SW}\end{array}$ & $\begin{array}{c}\mathrm{NE}- \\
\mathrm{SE} \\
\end{array}$ & $\begin{array}{r}\mathrm{SW}- \\
\mathrm{SE} \\
\end{array}$ \\
\hline & & & \multicolumn{6}{|c|}{ Bay of Bengal } & \multicolumn{6}{|c|}{ Arabian Sea } \\
\hline \multirow[t]{8}{*}{$34 / 17$} & Pre-M & CS & & & & & & & & & & & & \\
\hline & & SCS & 01 & 05 & 01 & & & & & & & & & \\
\hline & & VSCS & 05 & 05 & 01 & & & & & 05 & & 01 & & \\
\hline & & $\mathrm{SuCS}$ & & & & & & & & & & & & \\
\hline & Post-M & CS & & 05 & 05 & & 05 & & & & & & & \\
\hline & & SCS & & & 01 & 05 & 01 & 05 & & & & & & \\
\hline & & VSCS & & 05 & 05 & 05 & & & & & & & & \\
\hline & & $\mathrm{SuCS}$ & 05 & 01 & & 01 & & 05 & & & & & & \\
\hline \multirow[t]{6}{*}{$50 / 26$} & Pre-M & SCS & & & & & & & & & & & & \\
\hline & & VSCS & & & & & 05 & & & & & & & \\
\hline & & $\mathrm{SuCS}$ & & & & & & & & & & & & \\
\hline & Post-M & SCS & & & & & & & & & & & & \\
\hline & & VSCS & & & & & & & & & & & & \\
\hline & & $\mathrm{SuCS}$ & & 05 & & 01 & & & & & & & & \\
\hline \multirow[t]{4}{*}{$64 / 33$} & Pre-M & VSCS & & & & & & & & & & & & \\
\hline & & $\mathrm{SuCS}$ & & & & & & & & & & & & \\
\hline & Post-M & VSCS & & & & & & & & & & & & \\
\hline & & SuCS & 05 & & & 01 & & & & & & & & \\
\hline
\end{tabular}

CS: cyclonic storm, SCS: severe CS, VSCS: very severe CS, SuCS: super CS, NW: northwest,

NE: northeast, SW: southwest, SE: southeast, Pre-M: pre-monsoon, Post-M: post-monsoon.

sector in some cases to left rear sector in other cases. The size of the TC was found to be asymmetrical with radius of $34(17)$ knot $\left(\mathrm{ms}^{-1}\right)$ wind being maximum in NE quadrant and minimum in SW quadrant. As there was no segregation of data based on basin, season and intensity, it is difficult to make more specific conclusions from this study. Colon et al. (1970) analyzed the structure of the TC based on the only TC over the AS on 22nd May 1963 using aircraft reconnaissance. According to him, the low level wind field showed a band of maximum winds $\left(>50(26) \mathrm{knot}\left(\mathrm{ms}^{-1}\right)\right)$ at a height of $2000 \mathrm{ft}$ extending in a slightly spiralling configuration around the rear and right semi-circles. The radial position of this band varied considerably in different quadrants indicating asymmetry in wind distribution.

The larger mean wind radius in NE quadrant may be due to the fact that the TCs over the AS during pre-monsoon season occur in association with monsoon surge and inter-tropical convergence zone (ITCZ), which roughly runs along $10^{\circ} \mathrm{N}$ in the month of May (Rao 1976). In both these cases, the cross equatorial flow increases leading to increase in wind over NE quadrant. To illustrate the above, the wind distribution at surface level based on CIRA's multi-platform satellite observation during the life period of TC, Phet, a VSCS over AS during 31 May-7 June, 2010 is shown in figure 3 . It clearly indicates the cross equatorial flow being fetched into the NE quadrant of the TC. It goes against the earlier findings of Dean et al. (2009) that the size of a given TC may be primarily a function of the geometry of the disturbance that serves to initiate it rather than a property of the large-scale environment, as the cross equatorial flow is a large scale environment feature.

The role of $\mathrm{RH}$ has been examined during the life period of the TC. A typical example of the horizontal distribution of $\mathrm{RH}$ at $500 \mathrm{hPa}$ level during life period of TC, Phet is presented in figure 4 based on NCEP/NCAR Reanalysis-2. It is generally expected that the $\mathrm{RH}$ in and around the centre of TC would be high. However, it can been seen from figure 4 that the region of maximum $\mathrm{RH}$ varies during the life cycle of a TC and may be away from the centre of the TC. It may be due to the fact that the region of maximum $\mathrm{RH}$ depends on several factors including the stage of TC like developing, matured and dissipating stage, environmental conditions like vertical wind shear and location of embedded meso-scale vortices in the TC field, etc. For example, in the case of TCs with 


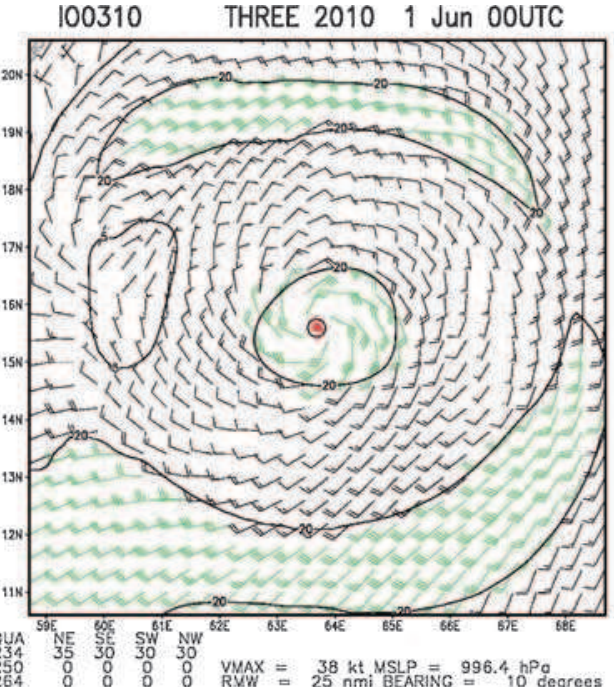

(a)

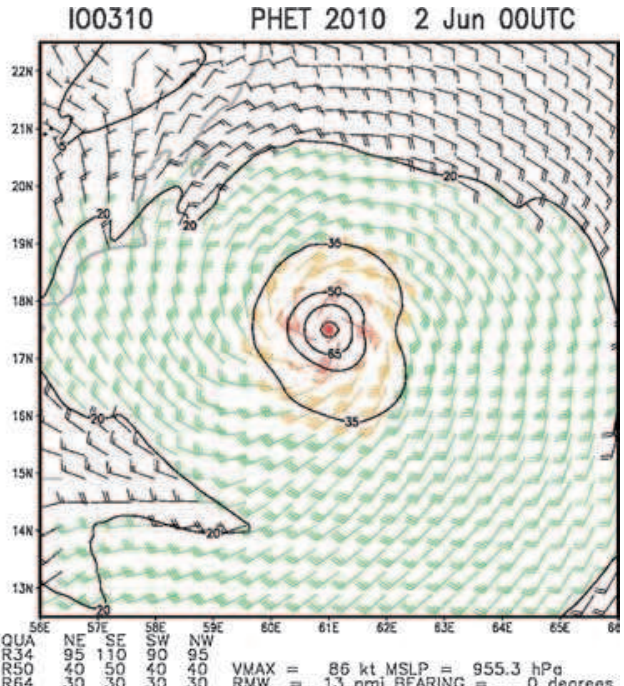

(a) $100310 \quad$ PHET $2010 \quad 3$ Jun OOUTC
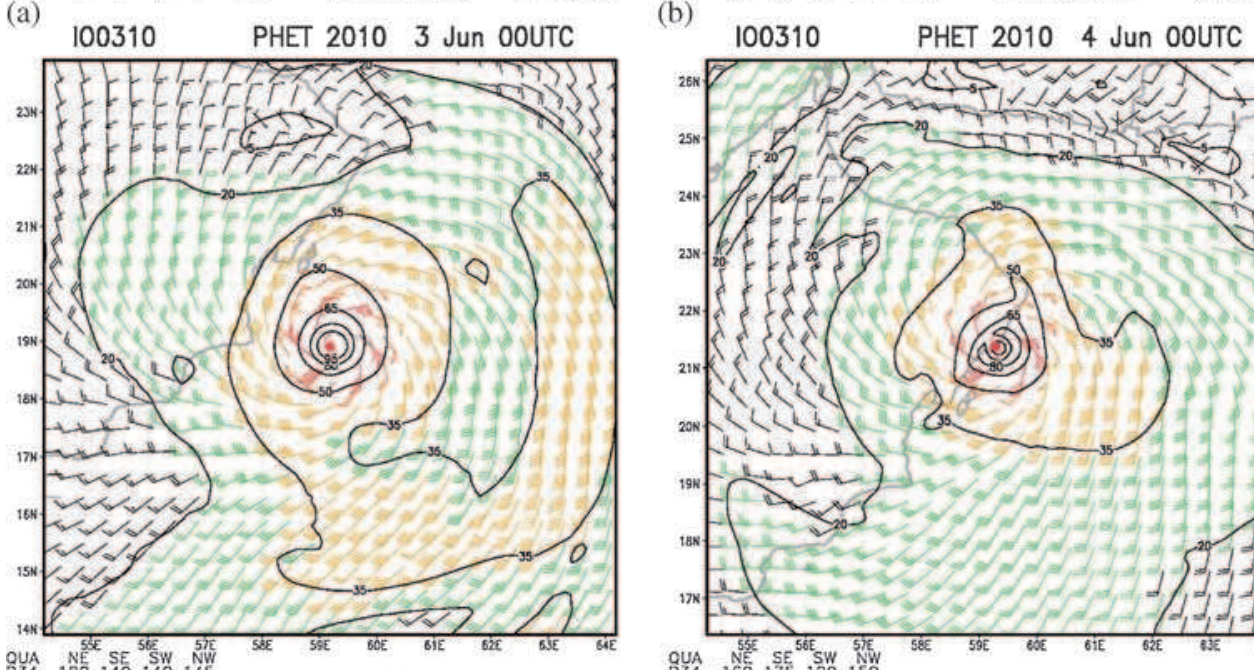

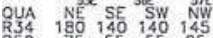

25.
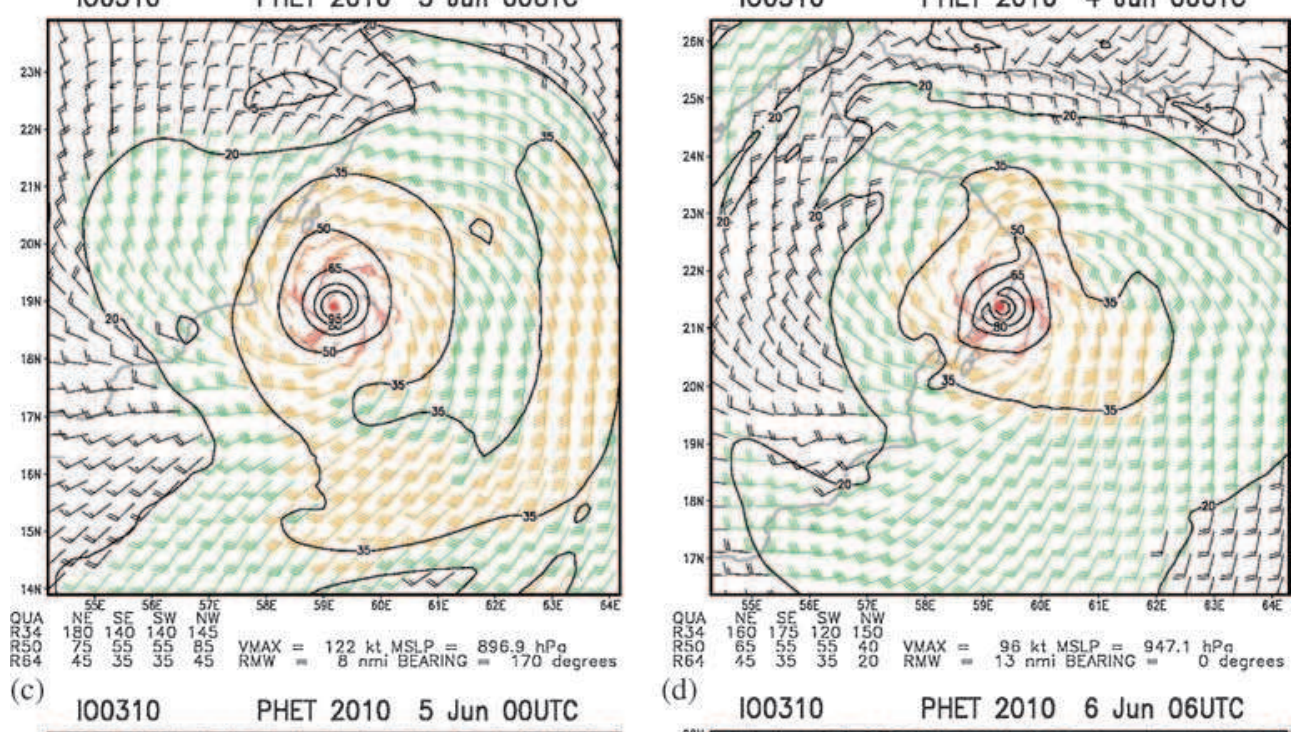

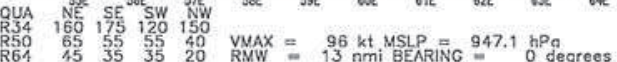

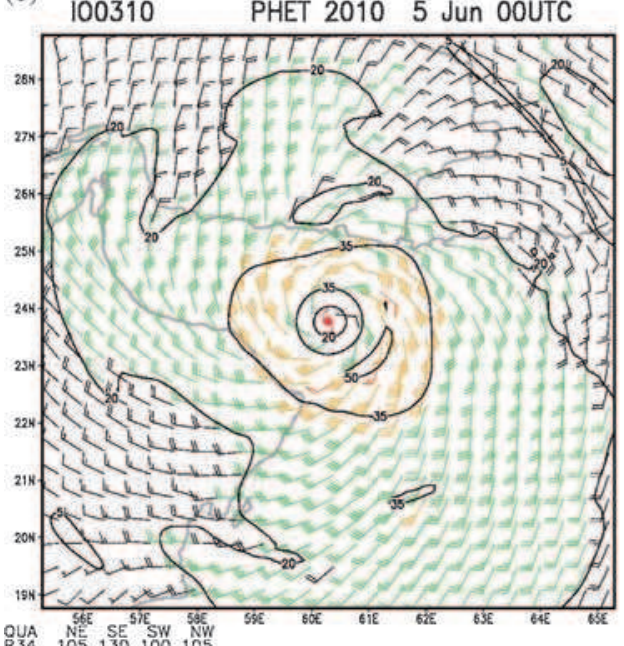

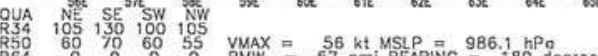

(e)

(d) $100310 \quad$ PHET $2010 \quad 6$ Jun O6UTC

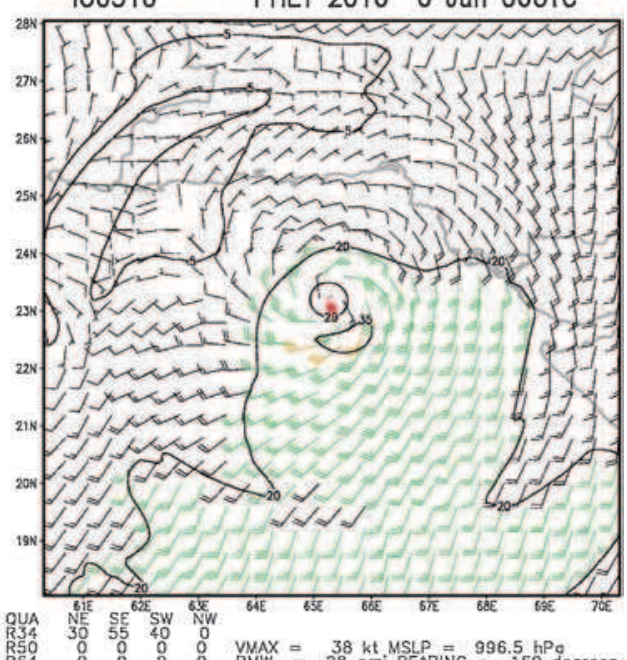

(f)

Figure 3. (a-f) Surface wind distribution at 0000 UTC of 1-6 June 2010 in association with very severe cyclonic storm, Phet over the Arabian Sea (31 May-7 June 2010). 
t: لدال1201000 7

Indiwidual obs rhum 安

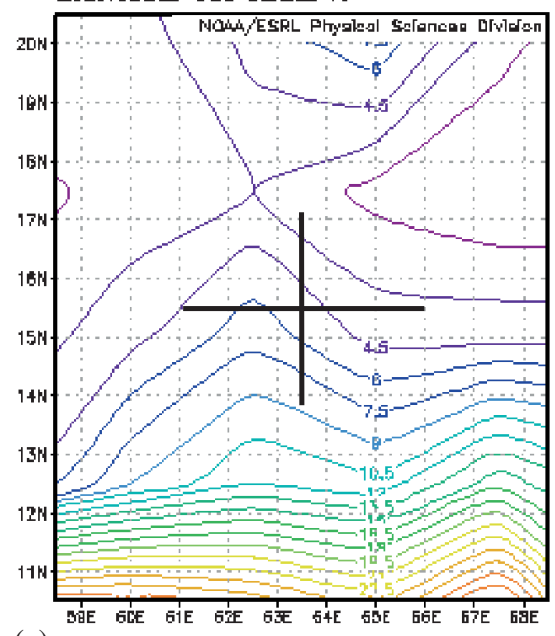

(a)

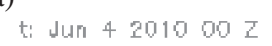

Indixidual oba rhum \%

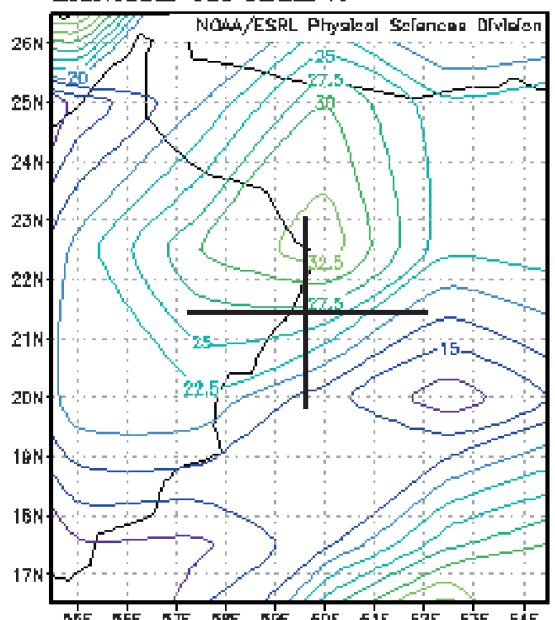

(d) t: لئ142010 $200 \mathrm{Z}$

Inditidual oba rhum $\%$

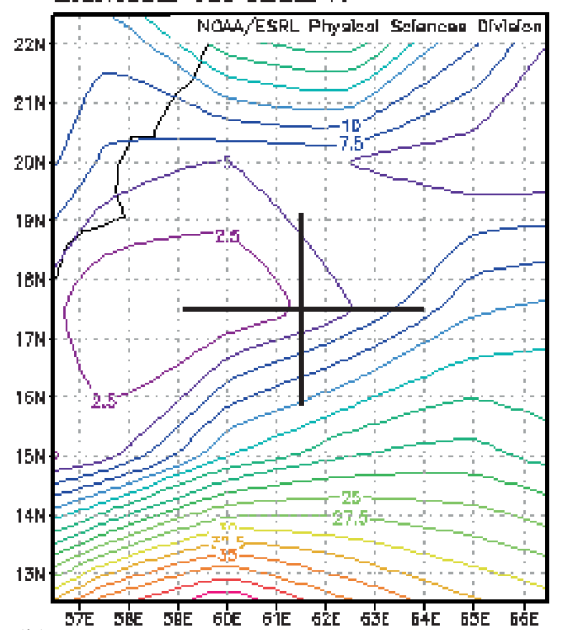

(b)

Inditidual oba rhum

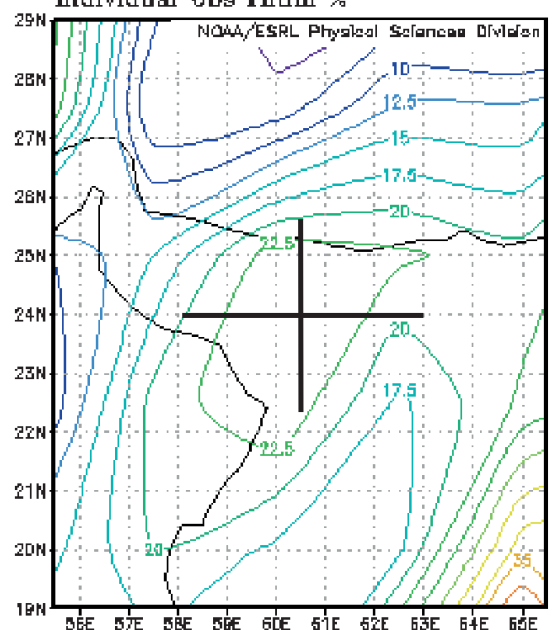

(e)

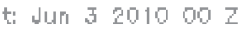

Indiwidual bba rhum \%

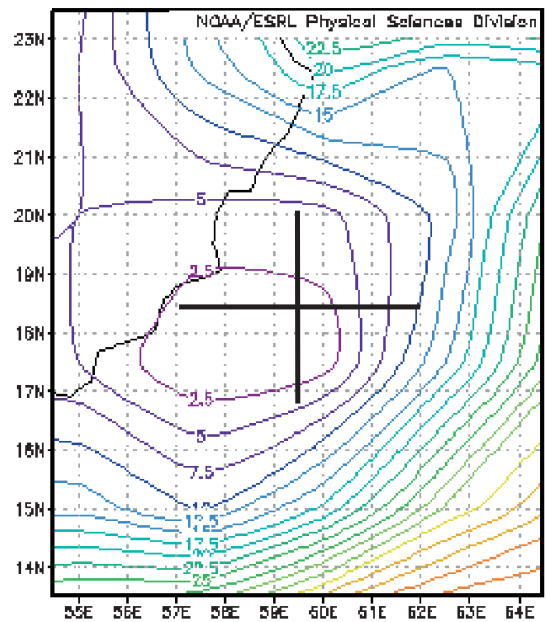

(c)

t: Jun $6201000 \mathrm{Z}$

Individual obs rhum \%

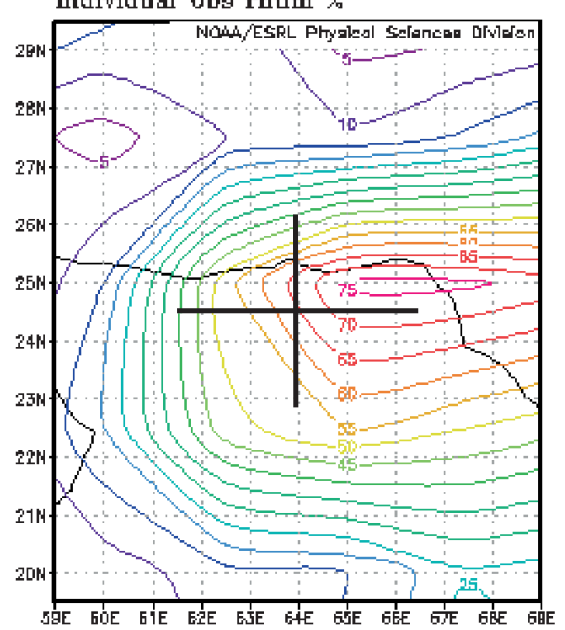

(f)

Figure 4. (a-f) Relative humidity at $500 \mathrm{hPa}$ level at 0000 UTC of 1-6 June 2010 in association with the very severe cyclonic storm, Phet over the Arabian Sea (1-7 June 2010). +: Centre of TC as per IMD best track.

convection sheared from the centre, which usually occurs in case of marginal TCs and developing $\mathrm{TCs}$, the centre of maximum $\mathrm{RH}$ may be different from the system centre. Comparing figures 2, 3 and 4 , the region of higher radial extent is in agreement with the region of higher RH. To analyze further the relation between $\mathrm{RH}$ and wind distribution, we have considered the vertical profile of $\mathrm{RH}$ at centre and four representative points in four geographical quadrants located at two degrees latitude and longitude away from the centre. The results are shown in figure $5(\mathrm{a}-\mathrm{d})$ for the representative TC, Phet over the AS during pre-monsoon season. It is found that quadrant with maximum R34 is same as the quadrants associated with maximum $\mathrm{RH}$ at lower tropospheric $(900-850 \mathrm{hPa})$ and middle tropospheric (500-400 hPa) levels on 2nd June, middle level on 3rd June and lower levels on 4th and 5th June, 2010. The RH has been maximum in $\mathrm{SE}$ followed by NE quadrant on 2-5 June in lower levels and in SE quadrant on 2 June and NE quadrant on 3-5 June in middle levels. Hence, asymmetry in wind structure of TC is reflected in the distribution of $\mathrm{RH}$ in lower and middle tropospheric levels also. Of course, the preferred level of maximum $\mathrm{RH}$ varies within the life cycle of a TC as well as from one $\mathrm{TC}$ to the other as it will be shown in next section.

\subsubsection{Size of $T C$}

When the CS intensifies into SCS stage, there is significant increase in size (radius of 34(17) knot $\left(\mathrm{ms}^{-1}\right)$ wind threshold) due to increase in radial extent in all quadrants at $1 \%$ level (table 4 ). When SCS intensifies into VSCS stage, the wind radius again significantly increases in all quadrants at 


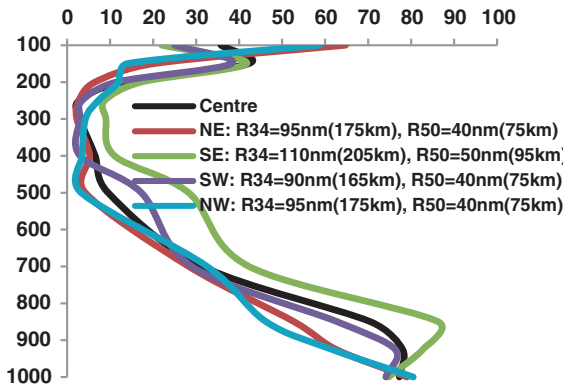

(a)

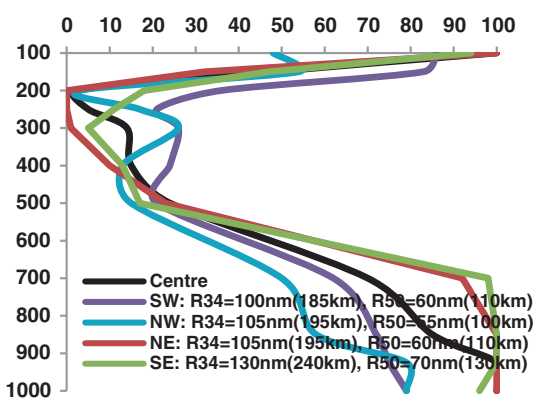

(d)

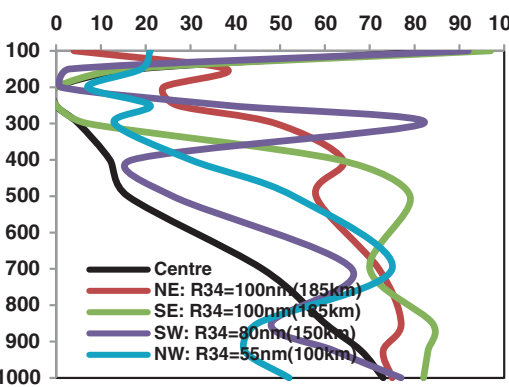

(g)

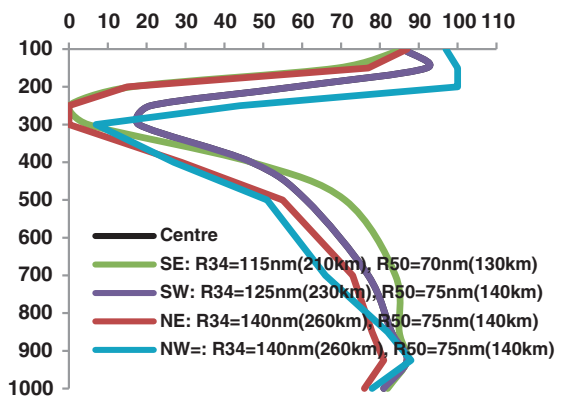

(j)

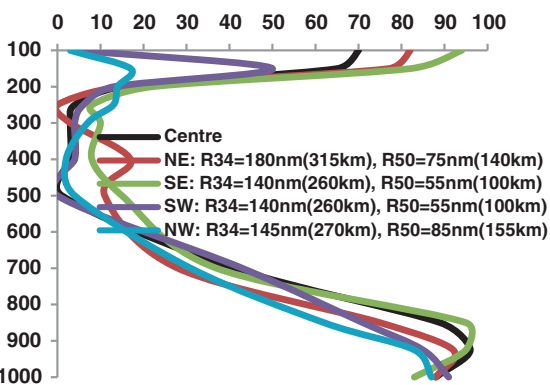

(b)

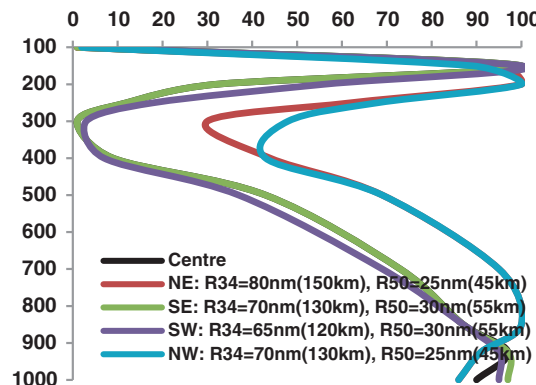

(e)

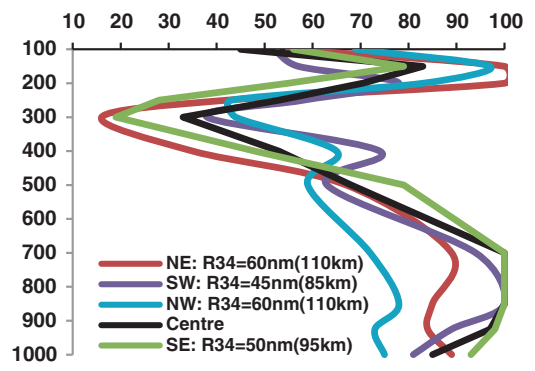

(h)

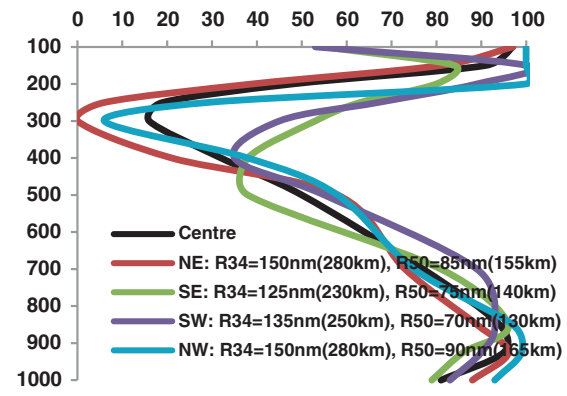

(k)

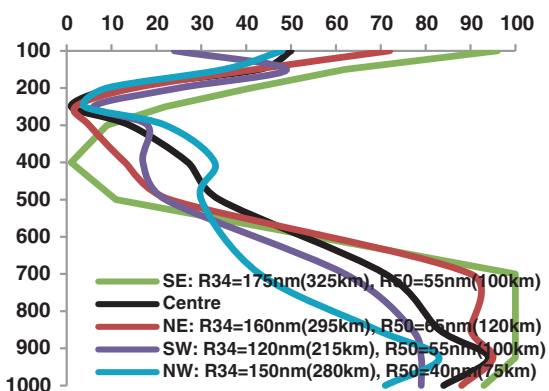

(c)

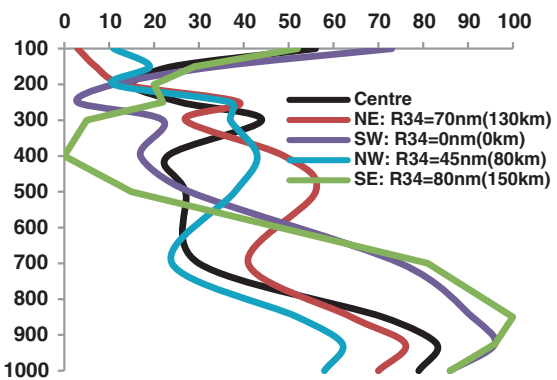

(f)

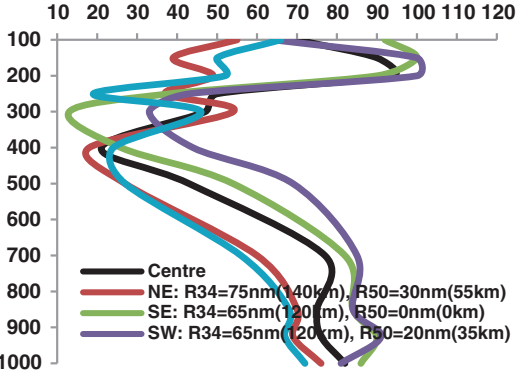

(i)

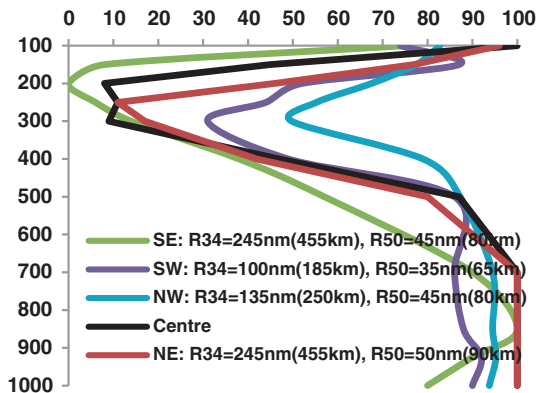

(1)

Figure 5. Relative humidity (\%) at standard isobaric levels at four representative points $\left(2^{\circ}\right.$ latitude/longitude away from the centre of TC) in four geographical quadrants of TC (a-d) 00 UTC of 2, 3, 4 and 5 June 2010 for Phet, (e) 00 UTC of 11 November 2009 for Phyan, (f-g) 06 UTC of 24 and 00 UTC of 25 May 2009 for Aila, and (h-1) 1200 UTC of 9th, 00 UTC of 10th, 11th, 12th and 13th October 2013 for Phailin.

$1 \%$ level (table 4). When the system intensifies from VSCS to SuCS stage, there is no significant change in size. Hence the size of the TC increases with increase in intensity upto VSCS stage. The size of the 50(26) knot $\left(\mathrm{ms}^{-1}\right)$ wind also significantly increases as the TC intensifies from SCS to VSCS stage. This observation on increase in size with increase in intensity goes against the fact over north Atlantic found by Frank (1977). According to him, while the inner structure of a TC often varies significantly both during the lifetime of a storm and across storms, the outer storm radius, defined as the radius at which the perturbation winds directly associated with the storm vanish, is believed to remain relatively constant during a storm's lifetime. 
4.2 Mean pattern of surface wind radii of TCs over the AS during post-monsoon season

\subsubsection{Asymmetry in wind distribution}

Considering the $34(17)$ knot $\left(\mathrm{ms}^{-1}\right)$ wind radii associated with CS (table 5, figure 6), it is maximum in SE (107(198) $\mathrm{nm}(\mathrm{km})$ followed by SW quadrant $(83(154) \mathrm{nm}(\mathrm{km}))$ and minimum over NE quadrant $(63(117) \mathrm{nm}(\mathrm{km}))$. However, the difference in mean wind radii for any two geographical quadrants is not statistically significant at $5 \%$ level (table 3$)$. The 34(17) knot $\left(\mathrm{ms}^{-1}\right)$ wind radius in case of SCS, becomes maximum in NE followed by NW quadrant and minimum in SW quadrant

Table 4. Level of significance (\%) in difference of mean wind radii with intensification of tropical cyclones over the Bay of Bengal and Arabian Sea.

\begin{tabular}{|c|c|c|c|c|c|}
\hline \multirow{2}{*}{$\begin{array}{l}\text { Wind threshold } \\
\left(\mathrm{knot} / \mathrm{ms}^{-1}\right)\end{array}$} & \multirow[b]{2}{*}{ Basin } & \multirow[b]{2}{*}{ Season } & \multicolumn{3}{|c|}{$\begin{array}{l}\text { Level of significance }(\%) \text { in change in wind radii in different quadrants and } \\
\text { average radii with change in intensity }\end{array}$} \\
\hline & & & CS to SCS & SCS to VSCS & VSCS to SuCS \\
\hline \multirow[t]{4}{*}{$34 / 17$} & $\mathrm{BOB}$ & Pre-M & NS & $\begin{array}{l}1 \% \text { level for all quadrants } \\
\text { and average radii }\end{array}$ & DNA \\
\hline & $\mathrm{BOB}$ & Post-M & $\begin{array}{l}1 \% \text { level: NW, NE } \\
\text { and } 5 \% \text { level: } \mathrm{SE} \\
\text { and average radii }\end{array}$ & $\begin{array}{l}1 \% \text { level for all quadrants } \\
\text { and average radii }\end{array}$ & $\begin{array}{l}1 \% \text { level: } \mathrm{SW}, \mathrm{SE}, \mathrm{NE} \text {, } \\
\text { average and } 5 \% \text { level: } \\
\mathrm{NW} \text { radii }\end{array}$ \\
\hline & $\mathrm{AS}$ & Pre-M & $\begin{array}{l}1 \% \text { level for all } \\
\text { quadrants and } \\
\text { average radii }\end{array}$ & $\begin{array}{l}1 \% \text { level for all quadrants } \\
\text { and average radii }\end{array}$ & NS \\
\hline & $\mathrm{AS}$ & Post-M & $\mathrm{NS}$ & DNA & DNA \\
\hline \multirow[t]{4}{*}{$50 / 26$} & $\mathrm{BOB}$ & Pre-M & NA & $\begin{array}{l}1 \% \text { level: } \mathrm{NE}, \mathrm{SW} \text { and } \\
\text { average radii }\end{array}$ & NA \\
\hline & $\mathrm{BOB}$ & Post-M & NA & $\begin{array}{l}1 \% \text { level for all quadrants } \\
\text { and average radii }\end{array}$ & $\begin{array}{l}1 \% \text { level for all quadrants } \\
\text { and average radii }\end{array}$ \\
\hline & $\mathrm{AS}$ & Pre-M & NA & $\begin{array}{l}1 \% \text { level for all quadrants } \\
\text { and average radii }\end{array}$ & NS \\
\hline & $\mathrm{AS}$ & Post-M & NA & DNA & DNA \\
\hline \multirow[t]{4}{*}{$64 / 33$} & $\mathrm{BOB}$ & Pre-M & NA & NA & DNA \\
\hline & $\mathrm{BOB}$ & Post-M & NA & NA & $\begin{array}{l}1 \% \text { level for all quadrants } \\
\text { and average radii }\end{array}$ \\
\hline & $\mathrm{AS}$ & Pre-M & NA & NA & NS \\
\hline & AS & Post-M & NA & NA & DNA \\
\hline
\end{tabular}

AS: Arabian Sea, BOB: Bay of Bengal.

CS: cyclonic storm, SCS: severe CS, VSCS: very severe CS, SuCS: super CS.

NW: northwest, NE: northeast, SW: southwest, SE: southeast.

Pre-M: pre-monsoon, Post-M: post-monsoon.

DNA: data not available.

NA: not applicable as MSW with CS is $<50(26) \operatorname{knot}\left(\mathrm{ms}^{-1}\right)$ and SCS is $<64(33) \mathrm{knot}\left(\mathrm{ms}^{-1}\right)$.

NS: not significant at $5 \%$ level.

Table 5. Mean wind radii $(\mathrm{nm} / \mathrm{km})$ in four quadrants of a tropical cyclone over the Arabian Sea during post-monsoon season.

\begin{tabular}{|c|c|c|c|c|c|c|c|c|c|c|c|}
\hline \multirow{2}{*}{$\begin{array}{l}\text { Wind threshold } \\
\left(\mathrm{knot} / \mathrm{ms}^{-1}\right)\end{array}$} & \multirow{2}{*}{ Category } & \multicolumn{5}{|c|}{ Mean wind radii $(\mathrm{nm} / \mathrm{km})$} & \multicolumn{5}{|c|}{ Standard deviation $(\mathrm{nm} / \mathrm{km})$} \\
\hline & & NW & $\mathrm{NE}$ & SW & $\mathrm{SE}$ & Mean & NW & $\mathrm{NE}$ & SW & $\mathrm{SE}$ & Mean \\
\hline \multirow[t]{2}{*}{$34 / 17$} & $\mathrm{CS}$ & $71 / 131(8)$ & $63 / 117(10)$ & $83 / 154(6)$ & $107 / 198(6)$ & $71.8 / 133$ & $79 / 146$ & $70 / 130$ & $96 / 178$ & $117 / 217$ & $76.9 / 142$ \\
\hline & SCS & $73 / 135(2)$ & $78 / 145(2)$ & $55 / 102(2)$ & $68 / 126(2)$ & $68.1 / 126.1$ & $4 / 7.4$ & $4 / 7.4$ & $14 / 26$ & $4 / 7.4$ & $4.4 / 8.1$ \\
\hline $50 / 26$ & SCS & $25 / 46(2)$ & $25 / 46(2)$ & $25 / 46(2)$ & $25 / 46(1)$ & $25 / 46$ & - & - & - & - & - \\
\hline
\end{tabular}

CS: cyclonic storm, SCS: severe CS, VSCS: very severe CS, SuCS: super CS.

NW: northwest, NE: northeast, SW: southwest, SE: southeast.

Figures given within parentheses indicate the number of observations.

-: data not sufficient. 


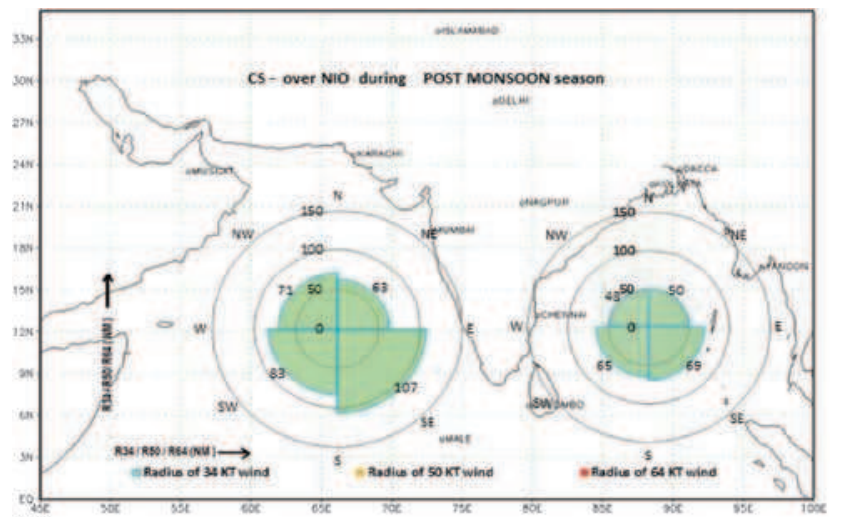

(a)

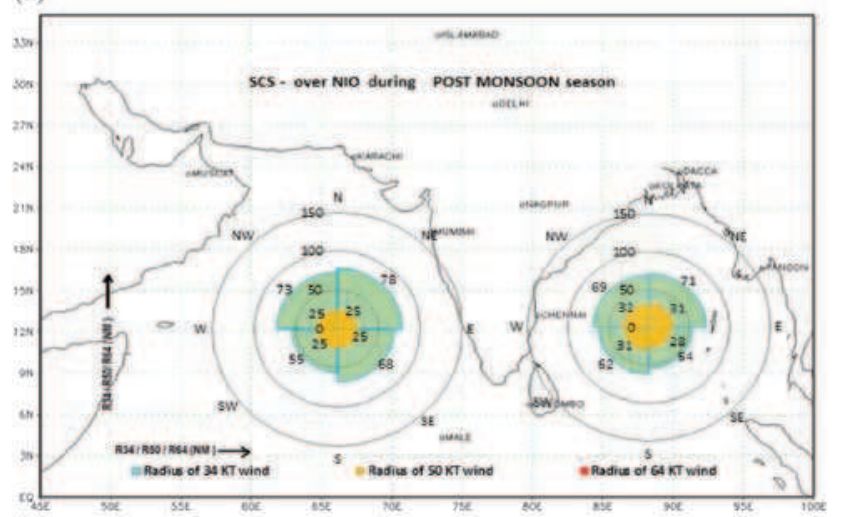

(b)

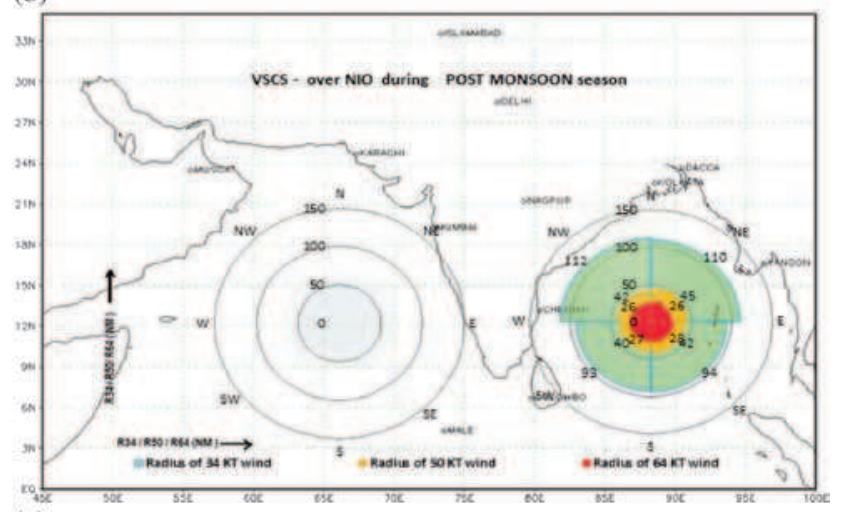

(c)

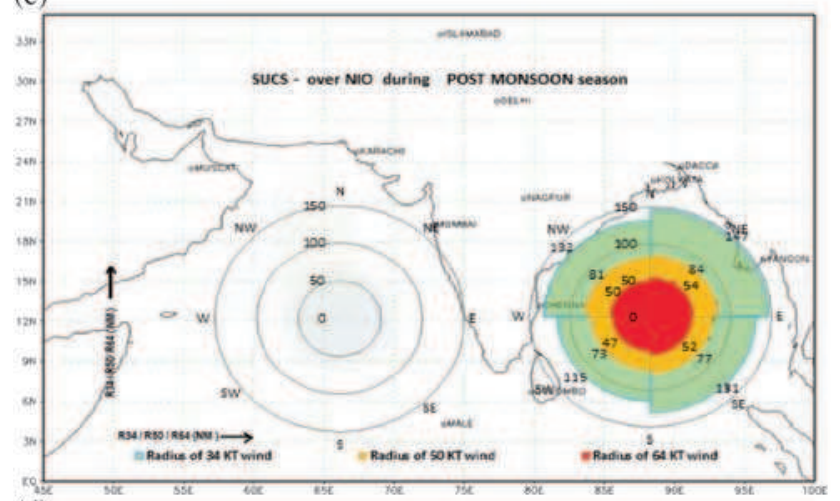

(d)

Figure 6. Quadrant radii of 34(17) (green), 50(26) (yellow) and 64(33) (red) knot $\left(\mathrm{ms}^{-1}\right)$ wind (R34, R50 and R64) in association with TCs of different intensities (a) CS, (b) SCS, (c) VSCS, and (d) SuCS during post-monsoon season. The values written inside each quadrant indicate mean R34, R50 and R64 (nm). (table 5), though there is no significant difference in radii in different quadrants at $5 \%$ level (table 3 ). Considering the 50(26) and 64(33) knot $\left(\mathrm{ms}^{-1}\right)$ wind threshold, there is no asymmetry in wind distribution like that in pre-monsoon season TCs over the AS. Hence, there is no significant asymmetry in wind distributions around the centre of TC over the AS during post-monsoon season for different thresholds, like 34(17), 50(26) and 64(33) $\left(\mathrm{ms}^{-1}\right)$ winds. It may be due to the fact that the wind distribution in post-monsoon TC is modulated by the combined effect of the forward speed of TC, cross equatorial flow and the northeast monsoon. To illustrate the above fact, the surface wind distribution in association with a postmonsoon TC, Phyan (9-12 November, 2009) over the AS is shown in figure 7 . To analyze the role of $\mathrm{RH}$, the horizontal distribution of $\mathrm{RH}$ at middle tropospheric level for TC, Phyan is shown in figure 8 and the vertical profile of $\mathrm{RH}$ at four representative points in four geographical quadrants of TC, Phyan are shown in figure 5(e). It is found that $\mathrm{RH}$ is maximum in NE quadrant in lower and middle levels at 0000 UTC of 11th November, 2009 which is also the quadrant of maximum R34. At 0600 and 1200 UTC of 11th November, 2009, the $\mathrm{RH}$ is maximum in NW followed by NE quadrant in middle levels (figure 8) and R34 is also maximum in NW quadrant (figure 6).

\subsubsection{Size of $T C$}

As the TC over the AS in post-monsoon season intensifies into SCS, the size of the TC (radius of $34(17)$ knot $\left(\mathrm{ms}^{-1}\right)$ wind) does not increase significantly unlike pre-monsoon season (tables 4 and 5). However, there is significant increase in size of inner core winds (50(26) knot $\left(\mathrm{ms}^{-1}\right)$ or more) when the CS intensifies into SCS. Dean et al. (2009) investigated the size distribution of Atlantic TCs, noting that the underlying internal and environmental factors that determine both individual storm size and the climatological size distribution remain enigmatic. It is argued that, in the absence of land interaction, the size of a storm is observed to vary only marginally during its lifetime prior to recurvature into the extra-tropics. However, significant variation exists between storms, regardless of basin, location and time of year. Considering the tracks of TCs over AS during post-monsoon season, it can be observed that there was northeastward recurvature of one of the three TCs under the influence of mid-latitude westerlies and the other two were not impacted by mid-latitude westerlies. Further, the land interaction is less over $\mathrm{AS}$, as most parts of the track lies over the sea area. 


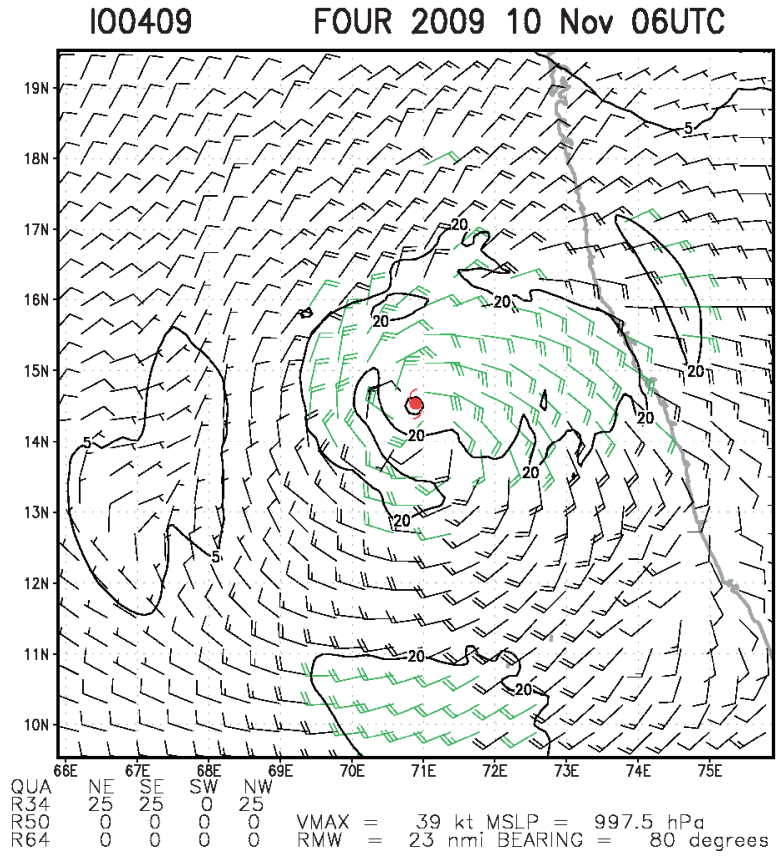

(a)

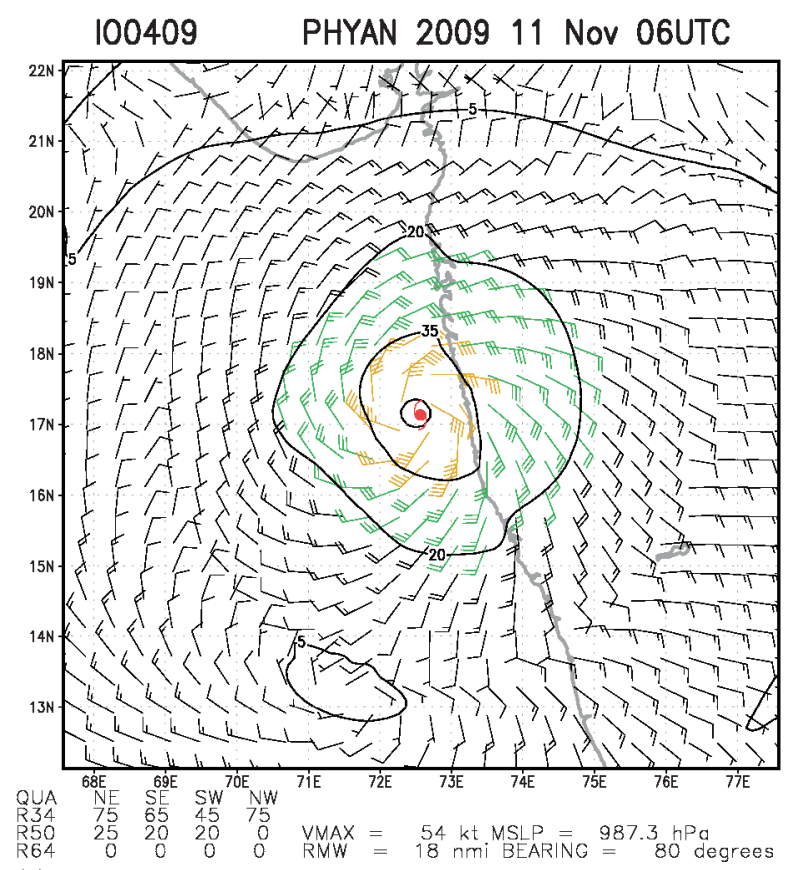

(c)

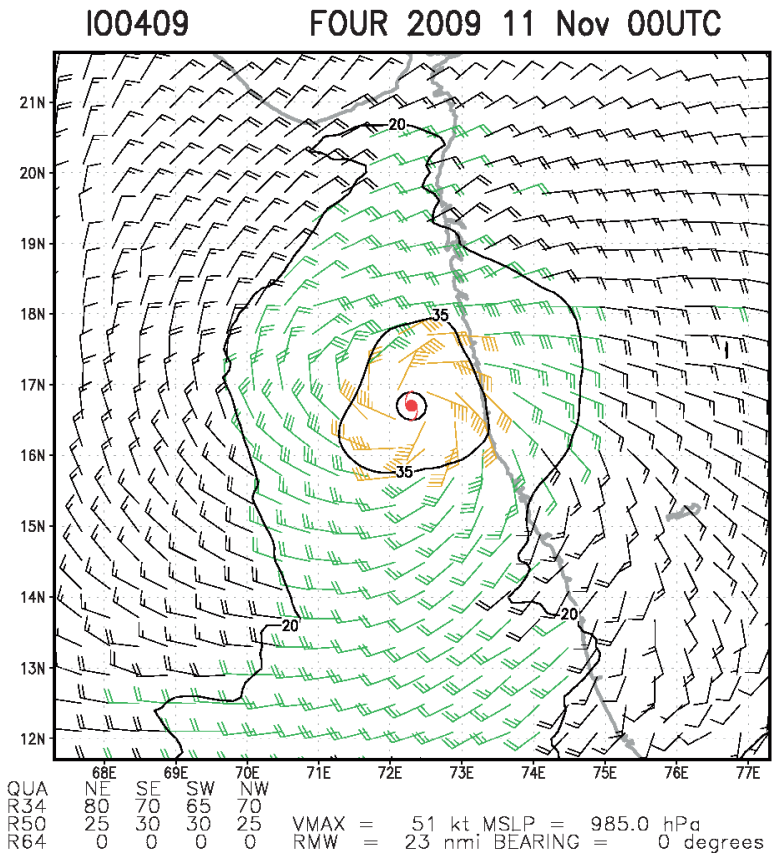

(b)

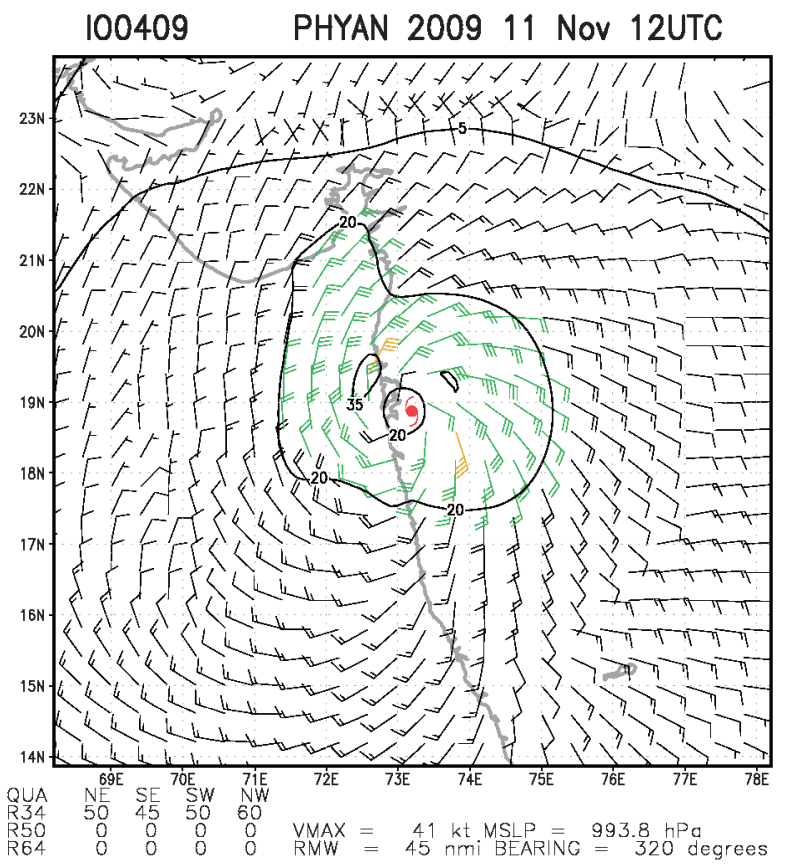

(d)

Figure 7. Surface wind distribution at (a) 0600 UTC of 10 November, (b) 0000, (c) 0600, and (d) 1200 UTC of 11 November, in association with cyclonic storm, Phyan over the Arabian Sea (9-12 November 2009).

\subsection{Mean pattern of surface wind radii of $B O B$ TCs during pre-monsoon season}

\subsubsection{Asymmetry in wind distribution}

The mean pattern of surface wind radii for four geographical quadrants of TCs over the BOB during pre-monsoon season with different intensities are shown along with the SDs in table 6 and figure 2. The 34(17) knot $\left(\mathrm{ms}^{-1}\right)$ wind radius in case of CS is maximum in SE quadrant (82(152) $\mathrm{nm}(\mathrm{km}))$ and minimum over NW quadrant (52(96) $\mathrm{nm}(\mathrm{km}))$. However, the asymmetry is not statistically significant at 5\% level. When the system intensifies into SCS, the asymmetry is significant at $5 \%$ level between NW and NE/SW/SE quadrants. The 34(17) knot $\left(\mathrm{ms}^{-1}\right)$ wind radius becomes maximum in SE (72(133) nm $(\mathrm{km}))$ and minimum over NW quadrant $(52(96) \mathrm{nm}(\mathrm{km}))$. The wind radius becomes maximum in SE (121(244) $\mathrm{nm}(\mathrm{km}))$ and minimum in NW $(89(165) \mathrm{nm}(\mathrm{km}))$ quadrant in 
t: Wa 102009 DE Z

Inditidual 0ba rhum \%

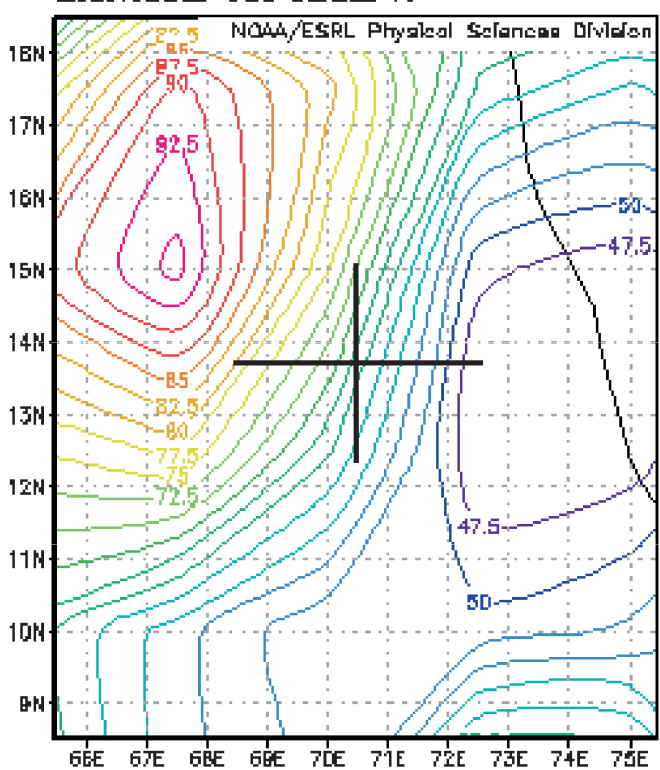

(a)

t: Now 11 2009 0E Z

Inditidual oba rhum \%

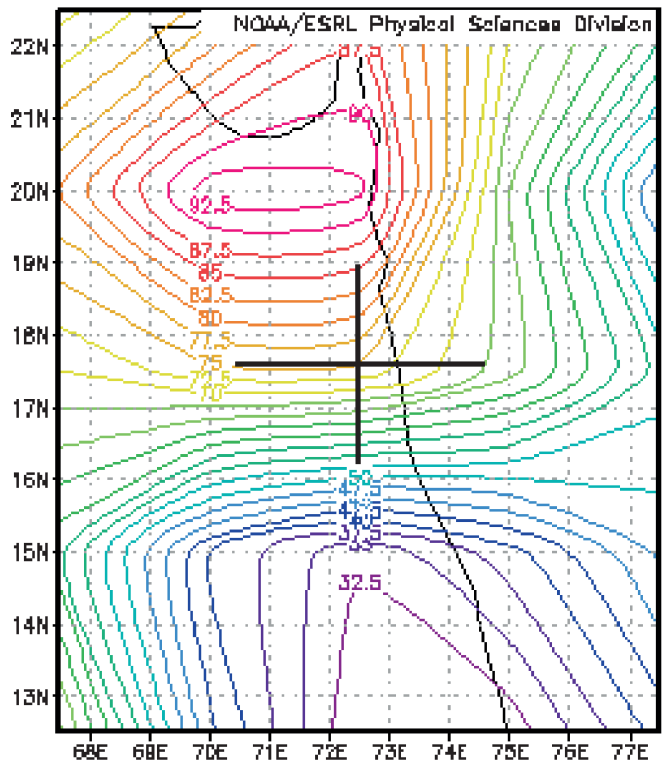

(c)

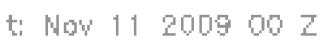

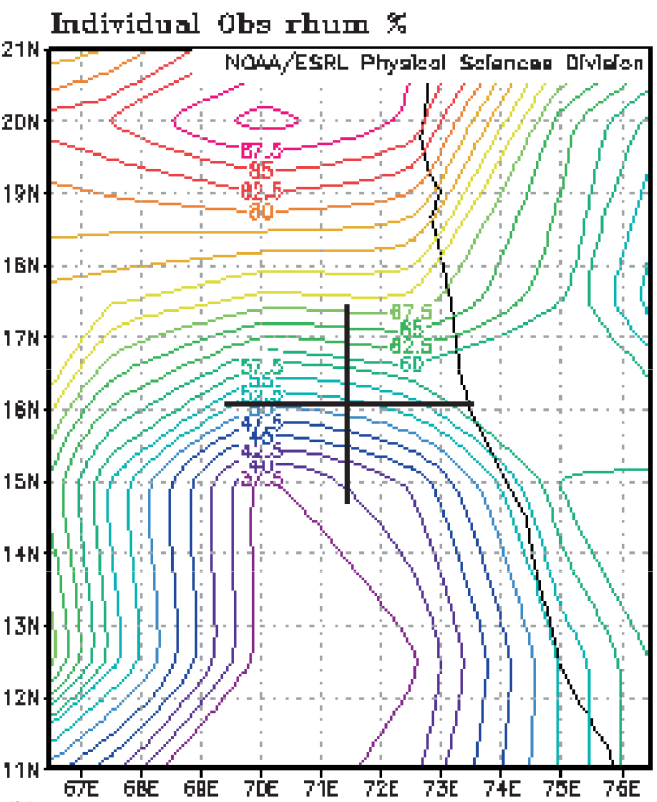

(b)

$$
\text { t: Wow } 11200912 z
$$

Inditidual oba rhum \%

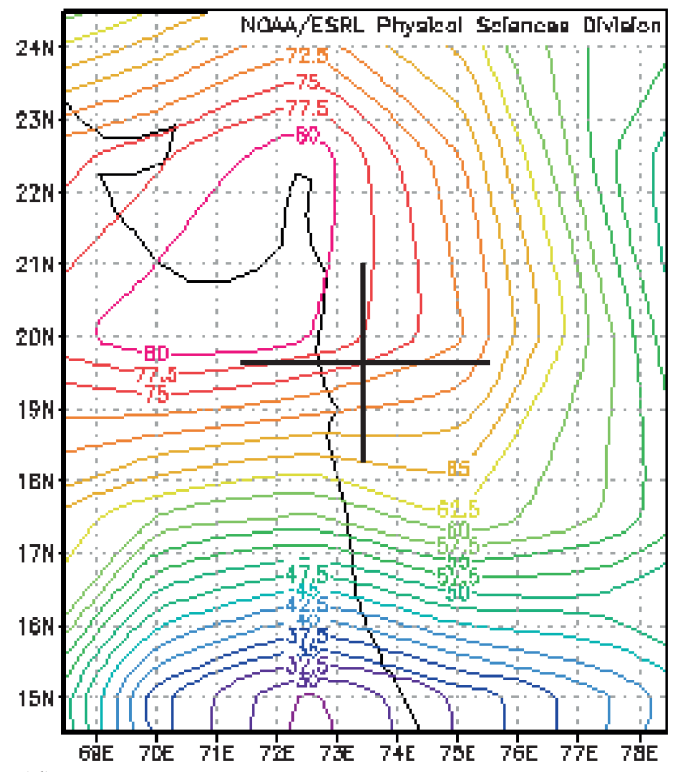

(d)

Figure 8. Relative humidity at $500 \mathrm{hPa}$ level at (a) 0600 UTC of 10 November and (b) 0000, (c) 0600 and (d) 1200 UTC of 11 November 2009 in association with the cyclonic storm, Phyan over the Arabian Sea (9-12 November 2009). +: Centre of TC as per IMD best track.

VSCS stage. The asymmetry is significant at 5\% level between NW and NE, NW and SW and at 1\% level between NW and SE quadrants. Thus, unlike TCs over the AS, the sector of larger wind radius does not change with intensification of the TC over the BOB in pre-monsoon season. The larger wind radius in SE quadrant may be due to the fact that the TCs over the BOB during pre-monsoon season occur mainly in association with monsoon surge and ITCZ, which roughly runs along $10^{\circ} \mathrm{N}$ in the month of May and early June. The frequency of TCs in pre-monsoon season is maximum in the month of May. In these cases, the cross equatorial flow increases leading to increase in wind over $\mathrm{SE}$ quadrant. It goes against the earlier findings of Dean et al. (2009) as mentioned in previous section 4.1.1. To illustrate it further, the multiplatform satellite-based surface wind in case of an SCS, Aila over the BOB during 23-26 May 2009, which occurred during onset phase of monsoon is 
Table 6. Mean wind radii $(\mathrm{nm} / \mathrm{km})$ in four quadrants of a tropical cyclone over the Bay of Bengal during pre-monsoon season.

\begin{tabular}{|c|c|c|c|c|c|c|c|c|c|c|c|}
\hline \multirow{2}{*}{$\begin{array}{l}\text { Wind } \\
\text { threshold } \\
\left(\mathrm{knot} / \mathrm{ms}^{-1}\right)\end{array}$} & \multirow[b]{2}{*}{ Category } & \multicolumn{5}{|c|}{ Mean wind radii $(\mathrm{nm} / \mathrm{km})$} & \multicolumn{5}{|c|}{ Standard deviation $(\mathrm{nm} / \mathrm{km})$} \\
\hline & & NW & $\mathrm{NE}$ & SW & $\mathrm{SE}$ & Mean & NW & $\mathrm{NE}$ & SW & $\mathrm{SE}$ & Mean \\
\hline \multirow[t]{3}{*}{$34 / 17$} & CS & $52 / 96(19)$ & $64 / 119(22)$ & 69/128(16) & $82 / 152(22)$ & $72.7 / 134.6$ & $44 / 81$ & $30 / 56$ & $72 / 133$ & $76 / 141$ & $48.5 / 90$ \\
\hline & SCS & $52 / 96(29)$ & $71 / 131(29)$ & $61 / 113(29)$ & $72 / 133(29)$ & $63.9 / 118.3$ & $16 / 30$ & $35 / 65$ & $20 / 37$ & $36 / 67$ & $23.1 / 43$ \\
\hline & VSCS & $89 / 165(24)$ & 104/193(24) & $114 / 211(24)$ & $121 / 224(24)$ & $107.0 / 198$ & $17 / 31$ & $32 / 59$ & $51 / 94$ & $43 / 80$ & $29.8 / 55$ \\
\hline \multirow[t]{2}{*}{$50 / 26$} & SCS & $32 / 59(6)$ & $31 / 57(13)$ & $29 / 54(8)$ & $43 / 80(16)$ & $31.7 / 58.7$ & $11 / 20$ & $12 / 22$ & $8 / 15$ & $50 / 93$ & $6.9 / 13$ \\
\hline & VSCS & $39 / 72(24)$ & $43 / 80(24)$ & $48 / 89(24)$ & $51 / 94(24)$ & $44.9 / 83$ & $9 / 17$ & $12 / 22$ & $21 / 39$ & $22 / 41$ & $14.6 / 27$ \\
\hline $64 / 33$ & VSCS & $24 / 44(23)$ & $25 / 46(22)$ & $26 / 48(23)$ & $27 / 50(24)$ & $25.7 / 48$ & $6 / 11$ & $5 / 9$ & $8 / 15$ & $9 / 17$ & $6.1 / 11$ \\
\hline
\end{tabular}

CS: cyclonic storm, SCS: severe CS, VSCS: very severe CS, SuCS: super CS.

NW: northwest, NE: northeast, SW: southwest, SE: southeast.

Figures given within parentheses indicate the number of observations.

shown in figure 9. To examine the role of $\mathrm{RH}$, the horizontal distribution of $\mathrm{RH}$ at middle level during life period of Aila are shown in figure 10 and vertical profiles of $\mathrm{RH}$ are shown in figure $5(\mathrm{f}-\mathrm{g})$. While the $\mathrm{RH}$ is maximum in $\mathrm{SE}$ followed by $\mathrm{NE}$ quadrant in lower and middle levels on 24th and 25th May, 2009 (figure $5 \mathrm{f}-\mathrm{g}$ ), the R34 is also maximum in SE followed by NE quadrant (table 6 , figure 2).

Considering the 50(26) knot $\left(\mathrm{ms}^{-1}\right)$ wind radii, the asymmetry decreases. However, the radial extent is maximum in SE quadrant in case of SCS and VSCS like that of $34(17)$ knot $\left(\mathrm{ms}^{-1}\right)$ wind radius (table 6 ). The difference in wind radii is significant only between NE and SE quadrants in case of SCS (table 3 ). Considering the wind radii of $64(33)$ knot $\left(\mathrm{ms}^{-1}\right)$ wind, the distribution is symmetrical about the centre of TC. Thus the asymmetry in outer core wind increases with intensification of TC, being symmetrical in CS stage and the radial extent is maximum in SE quadrant in SCS or higher intensity stage. The inner core winds of 50(26) and 64(33) knot $\left(\mathrm{ms}^{-1}\right)$ are symmetrical in case of VSCS or higher intensity TCs.

\subsubsection{Size of $T C$}

There is no significant change in size (34(17) knot $\left(\mathrm{ms}^{-1}\right)$ wind radius) when CS intensifies into SCS (table 4). When SCS intensifies into VSCS, the average size significantly increases along with that in all four quadrants at $1 \%$ level (table 4 ). Also there is significant increase in size of $50(26)$ knot $\left(\mathrm{ms}^{-1}\right)$ wind radii in NE and SW quadrants along with the average wind radii. Hence to conclude, the size of outer core as well as inner core winds increases significantly with increase in intensification of TC over BOB during pre-monsoon season.

\subsection{Mean pattern of surface wind radii of $B O B$ TCs during post-monsoon season}

\subsubsection{Asymmetry in wind distribution}

The 34(17) knot $\left(\mathrm{ms}^{-1}\right)$ wind distribution in case of the post-monsoon season TCs is shown in table 7 and figure 6 . The radial extent is maximum over SE $(69(128) \mathrm{nm}(\mathrm{km}))$ followed by SW (65(120) $\mathrm{nm}(\mathrm{km})$ ) quadrant and minimum over NW (48(89) $\mathrm{nm}(\mathrm{km}))$ quadrant. The asymmetry is significant at $5 \%$ level between NW and SW, NW and SE and $\mathrm{NE}$ and SE quadrants. As the CS intensifies into SCS, the radial extent becomes maximum in NE followed by NW quadrant and is minimum over SE quadrant. The asymmetry is significant at $1 \%$ level between NW and SE, NE and SE and at 5\% level between NE and SW quadrants. Hence, higher radial extent shifts from southern to northern sector as CS intensifies into SCS like that of TCs over the AS during post-monsoon season due to similar reasons. When SCS intensifies into VSCS, the asymmetry continues and is significant at $5 \%$ level between NW and SE, NW and SW and NE and SW quadrants. During VSCS stage, the wind radius is maximum over NW $(112(207) \mathrm{nm}(\mathrm{km}))$ followed by NE $(110(203) \mathrm{nm}(\mathrm{km}))$ quadrant. With intensification into SuCS stage, asymmetry is also significant at $1 \%$ level between NW and SW, NE and SW and at 5\% level between NW and NE and SW and SE quadrants. Thus the outer core winds are significantly asymmetric in all stages of intensity of TCs over the BOB during post-monsoon season. However, the region of higher radial extent shifts from southern sector in CS stage to northern sector in SCS/VSCS stage. The inner core winds are symmetrical around the centre.

According to Fujibe and Kitabatake (2007), asymmetries in the outer regions of the TC were related to strong TCs in a thermally asymmetric 


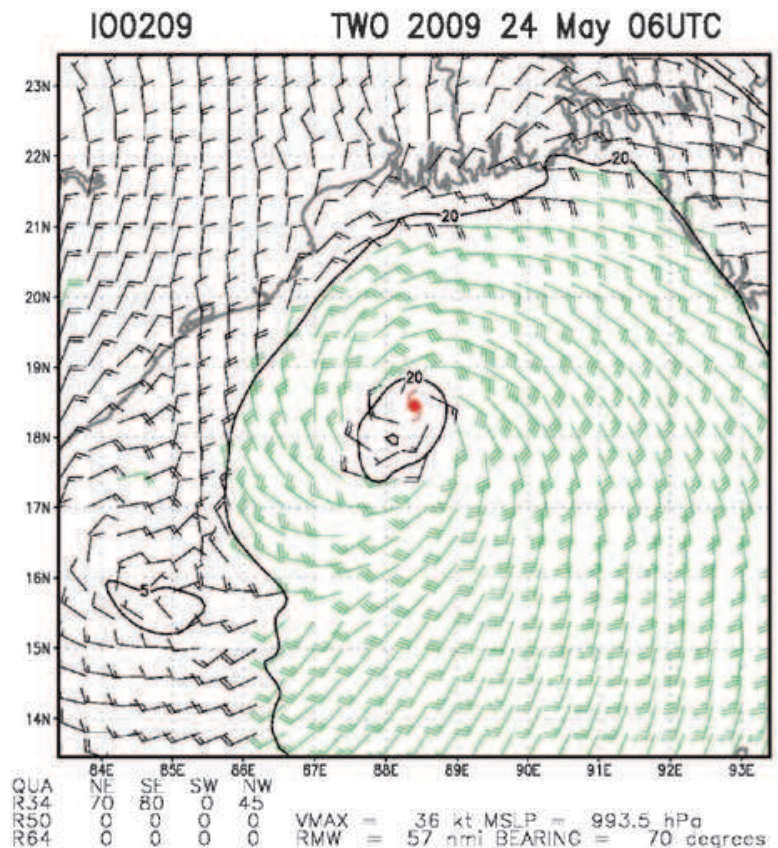

(a)
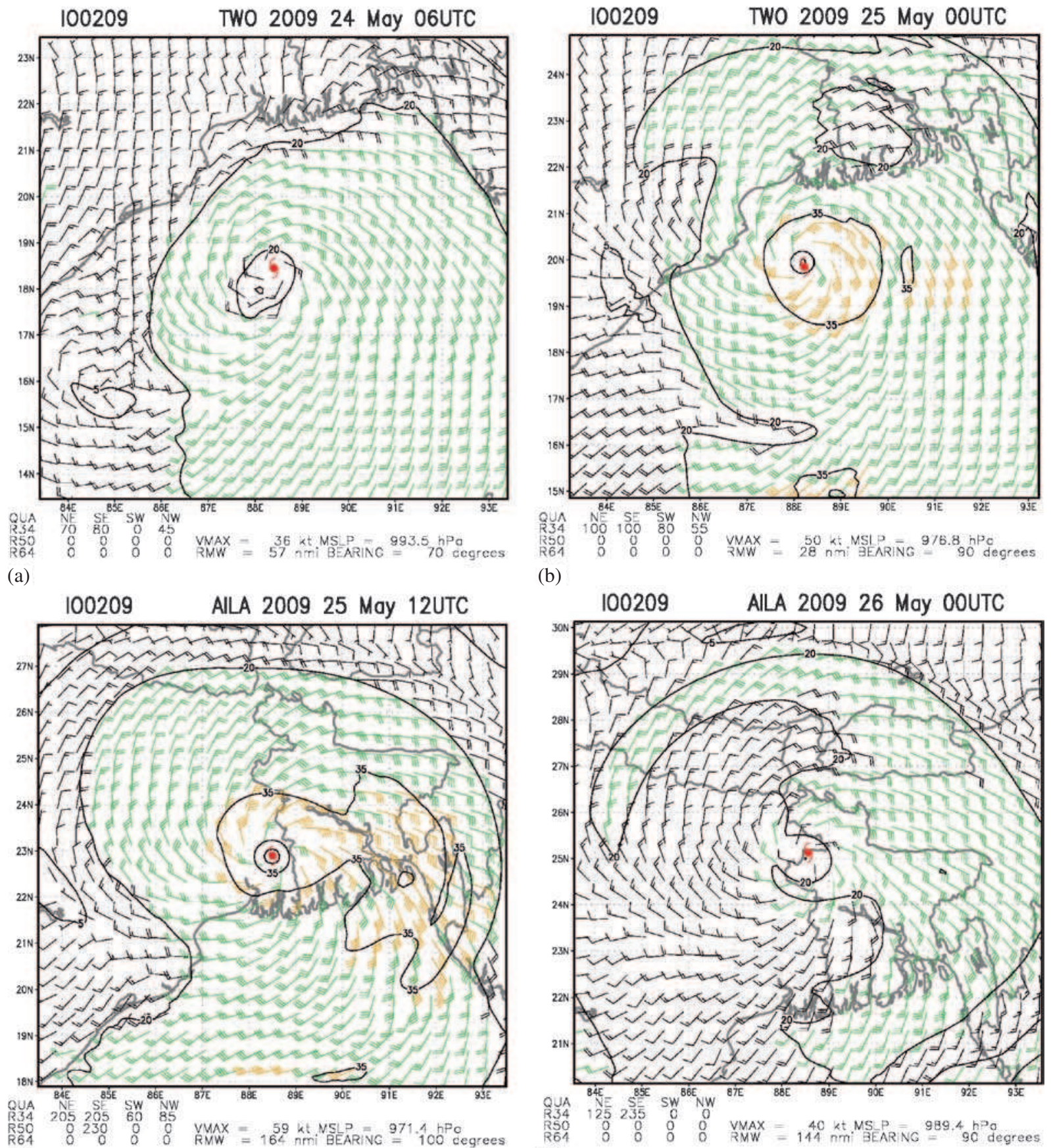

(b)

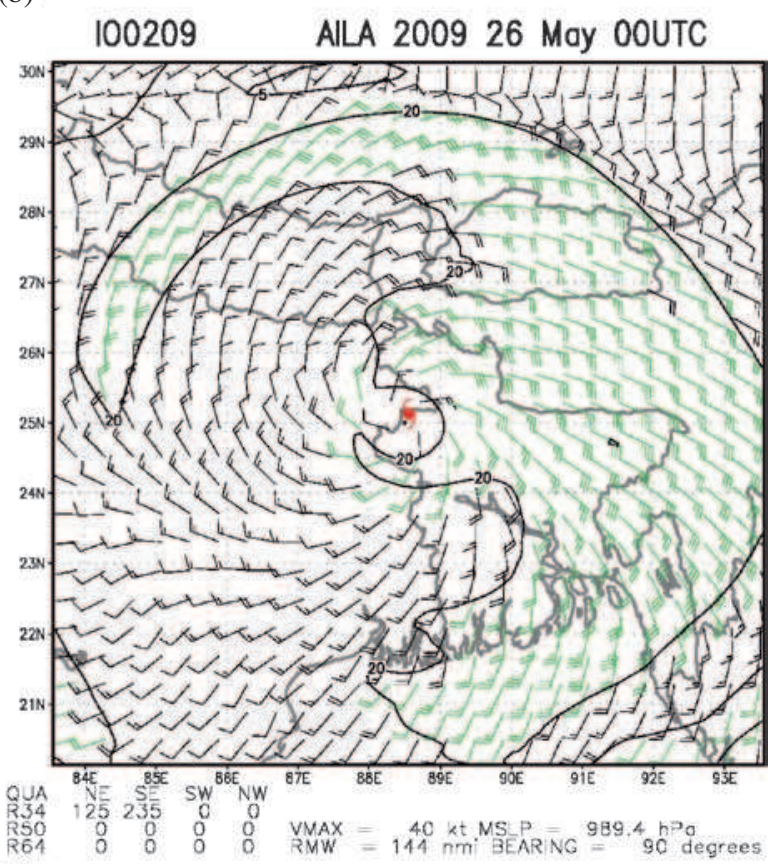

(c)

(d)

Figure 9. Surface wind distribution at (a) 0600 UTC of 24 May and (b) 0000 and (c) 1200 UTC of 25 May and (d) 0000 UTC of 26 May in association with severe cyclonic storm, Aila over the Bay of Bengal (23-26 May 2009).

environment. It is needless to mention that during the period of analysis, the BOB has witnessed stronger TCs in post-monsoon seasons as 8 out of 13 TCs were SCS/VSCS. Also the thermal asymmetry is higher over the BOB during post-monsoon season due to prevalence of northeast monsoon circulation to the south of $15^{\circ} \mathrm{N}$ and mid-latitude westerlies to the north of $20^{\circ} \mathrm{N}$. The SD is higher in case of 34(17) knot $\left(\mathrm{ms}^{-1}\right)$ wind radii over SW and SE quadrants in case of CS indicating large case to case variation like that of pre-monsoon CS over the BOB.

Considering 50(26) and 64(33) knot $\left(\mathrm{ms}^{-1}\right)$ wind radii, winds are almost symmetrical in case of SCS and VSCS with low SDs. According to Fujibe and Kitabatake (2007), symmetric inner core winds are associated with strong mature and symmetric TC. As mentioned in previous paragraph, the frequency 
t. Wy 242009 of I

Individual oba rhum \%

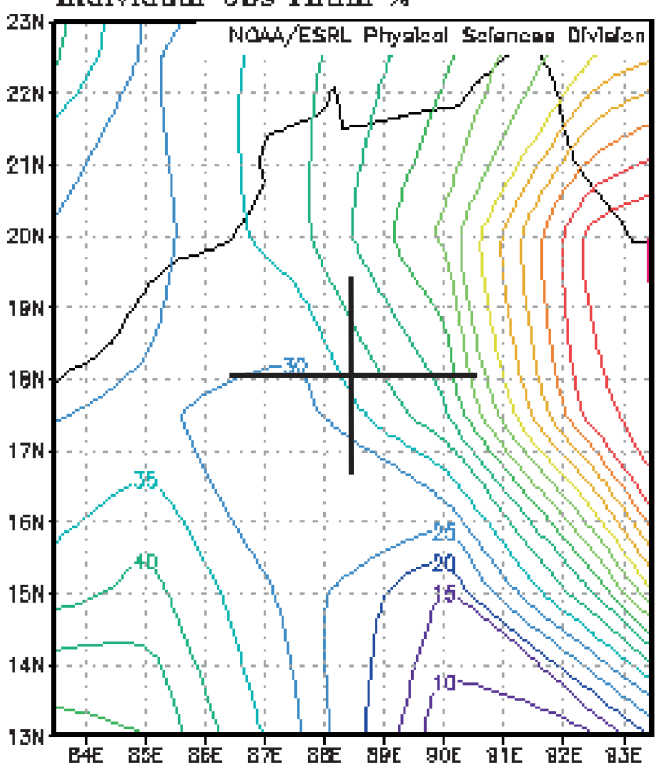

(a)

t: Wy $25200912 \quad 2$

Inditidual 0ba rhum \%

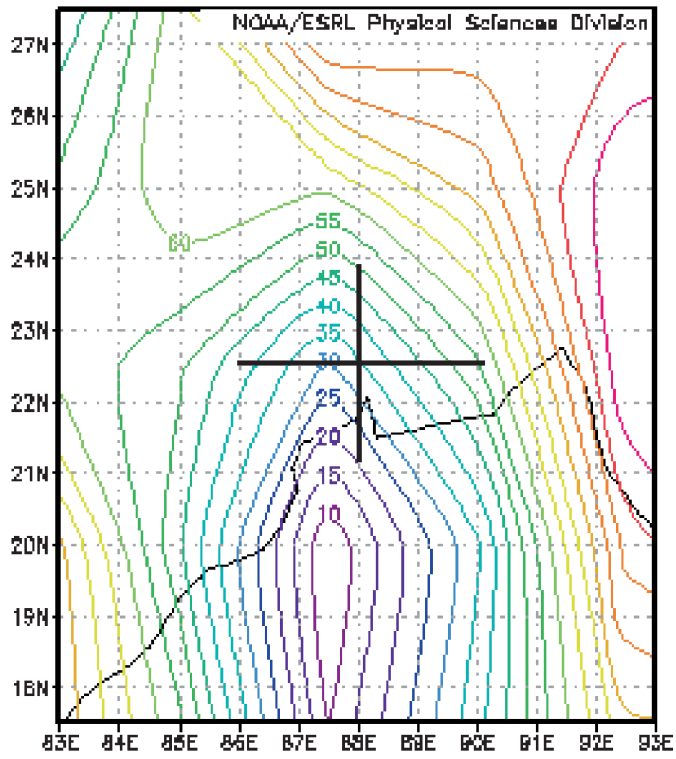

(c) t. Wy $25 \quad 2009$ OD 7

Inditidual obs rhum \%

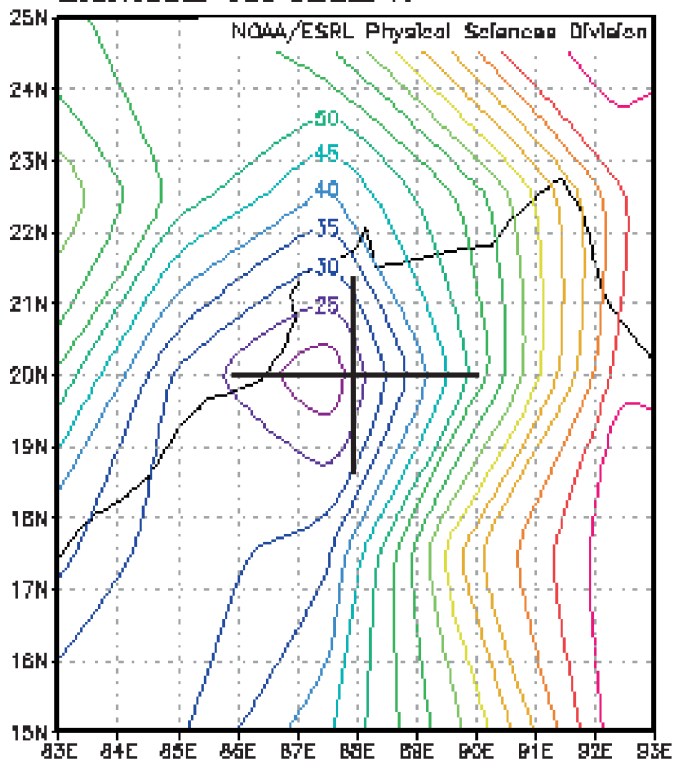

(b)

t. Wy $26 \quad 2009002$

Inditidual bba rhum \%

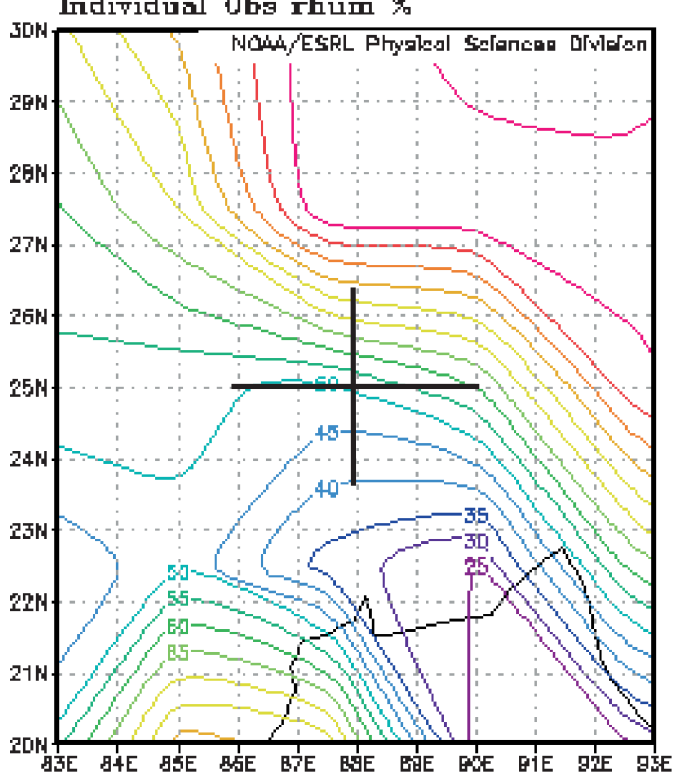

(d)

Figure 10. Relative humidity at $500 \mathrm{hPa}$ level at (a) 0600 UTC of 24 May and (b) 0000 and (c) 1200 UTC of 25 May and (d) 0000 UTC of 26 May 2009 in association with the severe cyclonic storm, AILA over the Bay of Bengal (23-26 May 2009). +: Centre of TC as per IMD best track.

of strong TCs (SCS/VSCS) was higher over BOB in post-monsoon season during 2007-2013 (period of study).

To examine the role of $\mathrm{RH}$ at lower and middle tropospheric levels on the asymmetry in wind distribution, the surface wind distribution and horizontal distribution of $\mathrm{RH}$ at middle levels in a representative TC, Phailin (9-13th October 2013) are shown in figures 11 and 12, respectively. The vertical profile of the $\mathrm{RH}$ in four geographical quadrants of TC, Phailin are shown in figure 5(h1). The quadrant of maximum R34 is same as the quadrant with maximum $\mathrm{RH}$ in lower levels at 0000 UTC of 11th and 13th and at both lower and middle levels on 12th October 2013. It is not in agreement at 1200 UTC of 9 th and 0000 UTC of 10th October 2013 (growing phase of TC, Phailin). 
Table 7. Mean wind radii $(\mathrm{nm} / \mathrm{km})$ in four quadrants of a tropical cyclone over the Bay of Bengal during post-monsoon season.

\begin{tabular}{|c|c|c|c|c|c|c|c|c|c|c|c|}
\hline \multirow{2}{*}{$\begin{array}{l}\text { Wind } \\
\text { threshold } \\
\text { (knot/ } \\
\mathrm{ms}^{-1} \text { ) }\end{array}$} & \multirow[b]{2}{*}{ Category } & \multicolumn{5}{|c|}{ Mean wind radii $(\mathrm{nm} / \mathrm{km})$} & \multicolumn{5}{|c|}{ Standard deviation $(\mathrm{nm} / \mathrm{km})$} \\
\hline & & NW & $\mathrm{NE}$ & SW & $\mathrm{SE}$ & Mean & NW & $\mathrm{NE}$ & SW & $\mathrm{SE}$ & Mean \\
\hline \multirow[t]{4}{*}{$34 / 17$} & CS & $48 / 89(52)$ & $50 / 93(54)$ & $65 / 120(40)$ & $69 / 128(44)$ & $57.0 / 105.6$ & $15 / 28$ & $20 / 37$ & $67 / 124$ & $74 / 137$ & $27.7 / 51.3$ \\
\hline & SCS & $69 / 128(52)$ & $71 / 131(52)$ & $62 / 115(52)$ & $54 / 100(52)$ & $64.0 / 118.5$ & $21 / 39$ & $19 / 35$ & $30 / 56$ & $15 / 28$ & $15.3 / 28.3$ \\
\hline & VSCS & $112 / 207(39)$ & $110 / 204(39)$ & $93 / 172(39)$ & $94 / 174(39)$ & $102.3 / 189.5$ & $41 / 76$ & $42 / 78$ & $31 / 57$ & $48 / 89$ & $32.5 / 60$ \\
\hline & $\mathrm{SuCS}$ & $132 / 245(16)$ & $147 / 272(16)$ & $115 / 213(16)$ & $131 / 243(16)$ & $131.2 / 243$ & $20 / 37$ & $29 / 54$ & $17 / 31$ & $30 / 56$ & $18.7 / 34.6$ \\
\hline \multirow[t]{3}{*}{$50 / 26$} & SCS & $32 / 59(35)$ & $31 / 57(39)$ & $31 / 57(28)$ & $28 / 52(32)$ & $30.3 / 56$ & $10 / 19$ & $8 / 15$ & $7 / 13$ & $9 / 17$ & $7.6 / 14.1$ \\
\hline & VSCS & $42 / 78(39)$ & $45 / 83(39)$ & $40 / 74(39)$ & $42 / 78(39)$ & $42.3 / 78$ & $13 / 24$ & $19 / 35$ & $14 / 26$ & $19 / 35$ & $15.3 / 28.3$ \\
\hline & SuCS & $81 / 150(16)$ & $84 / 156(16)$ & $73 / 135(16)$ & $77 / 143(16)$ & $78.5 / 145$ & $13 / 24$ & $12 / 22$ & $10 / 19$ & $11 / 20$ & $8.6 / 15.9$ \\
\hline \multirow[t]{2}{*}{$64 / 33$} & VSCS & $26 / 48(37)$ & $26 / 48(38)$ & $27 / 50(27)$ & $28 / 52(33)$ & $26.1 / 48$ & $9 / 17$ & $10 / 19$ & $11 / 20$ & $13 / 24$ & $9.7 / 18.0$ \\
\hline & SuCS & $50 / 93(16)$ & $54 / 100(16)$ & $47 / 87(16)$ & $52 / 96(16)$ & $50.4 / 93$ & $6 / 11$ & $6 / 11$ & $6 / 11$ & $6 / 11$ & $6.0 / 11.0$ \\
\hline
\end{tabular}

CS: cyclonic storm, SCS: severe CS, VSCS: very severe CS, SuCS: super CS.

NW: northwest, NE: northeast, SW: southwest, SE: southeast.

Figures given within parentheses indicate the number of observations.

\subsubsection{Size of $T C$}

As the CS intensifies into SCS, its size increases. The increase in size is significant in NW and NE quadrants at $1 \%$ level. The size of the storm continues to increase further, as it intensifies into VSCS, the increase is significant for all quadrants at $1 \%$ level (table 4). The significant increase in size of the TC with increase in intensity may be due to the fact that the BOB is a small basin and by the time the TC intensifies into SCS or above intensity, it interacts with the land surface, especially its outer core wind. Hence this finding endorses the earlier findings of Dean et al. (2009). To conclude, the size of both inner and outer core winds of the TC over the BOB during post-monsoon season increases significantly with increase in intensification of TCs.

According to Maclay et al. (2008), there are two primary types of growth processes: (i) secondary eyewall formation and eyewall replacement cycles; an internally dominated process, and (ii) external forcing from the synoptic environment. One of the most significant environmental forcings identified is the amount of vertical shear. Under light shear conditions, TCs appear to intensify but do not grow; under moderate shear, they intensify less but grow more; under very high shear, they do not intensify or grow. To examine the above in NIO scenario, a case study of VSCS, Phailin (8-14 October $2013)$ is presented here. The vertical wind shear during 9-13 October 2013 (figure 13) corresponding to the surface wind distribution (figure 11) are analyzed. It may be mentioned that, the VSCS, Phailin had rapid intensification from 0000 UTC of 10 th to 0000 UTC of 11 th October and then the intensity remained almost same till landfall though the size increased. It is found that the wind shear was low during 0000 UTC of 10 th to 0000 UTC of 11th October and became moderate subsequently. The size of $34(17)$ knot $\left(\mathrm{ms}^{-1}\right)$ wind radius increased from about $71(131)$ to $130(241)$ $\mathrm{nm}(\mathrm{km})$ from 0000 UTC of 10th to 0000 UTC of 11th October. Of course, there was another significant increase in size of the VSCS, Phailin from 0000 UTC of 12th to 0000 UTC of 13th October (during and after landfall) as the mean radius increased from $130(241)$ to $156(289) \mathrm{nm}(\mathrm{km})$ with much higher asymmetry in quadrant wind distribution (figure 11), mainly due to interaction with land surface, as Phailin crossed coast around 1700 UTC of 12th October 2013. There was eye wall replacement cycle also in case of Phailin, which commenced on 11th and ended on 12th October 2013. Hence this case study endorses the findings of Maclay et al. (2008) and Ueno (2008) on role of wind shear and findings of Dean et al. (2009) on the role of land interaction.

To find out the relation between the wind radii in different geographical quadrants and the vertical wind shear, the vertical wind shear at four representative points $\left(2^{\circ}\right.$ latitude/longitude away from the centre of TC in association with TC Phailin) are analyzed (table 8). It is found that the quadrant with maximum R34 coincides with minimum vertical wind shear, when the TC is over the sea and not interacting with land surface. However, when the TC lay over the land surface as on 13th October 2013 and is under relatively strong shear condition, the R34 was also higher in the quadrant associated with higher wind shear. The R34 was also higher in NE quadrant (right forward sector in relation to direction of motion of TC) in addition to the SE quadrant, which is associated with lowest wind shear. According to Ueno 


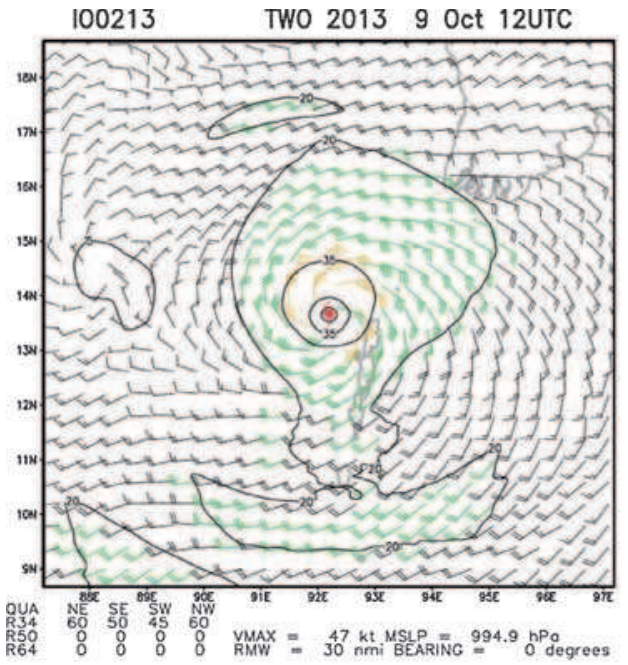

(a)

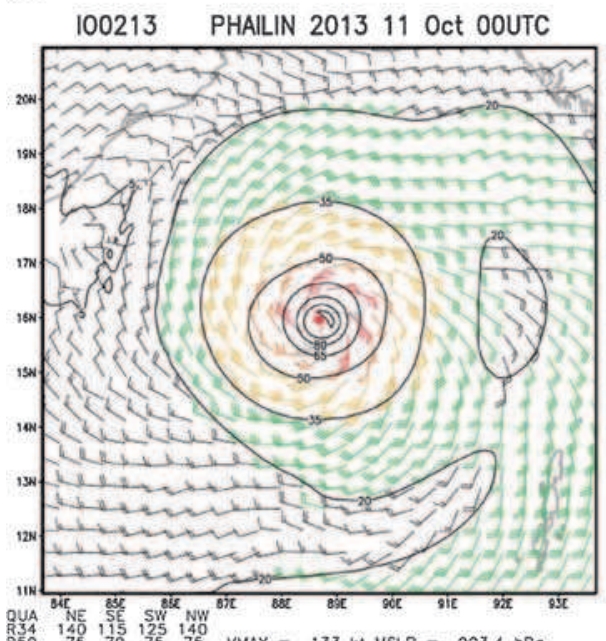

(c)

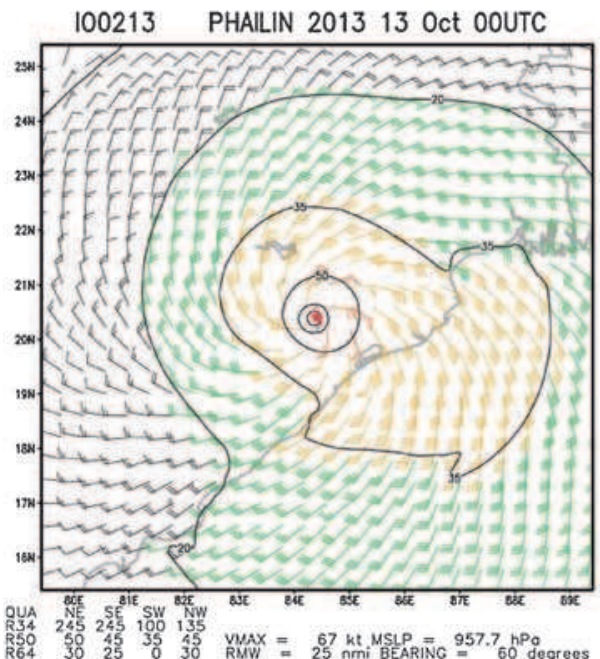

(e)
I00213 PHAILIN 201310 Oct OOUTC

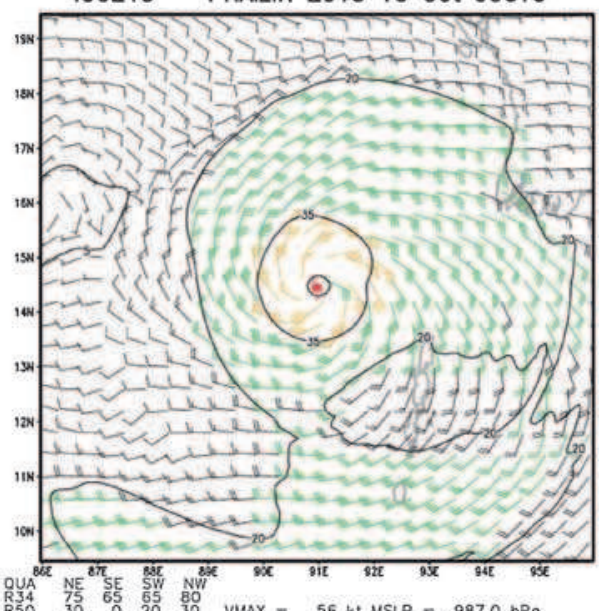

(b)

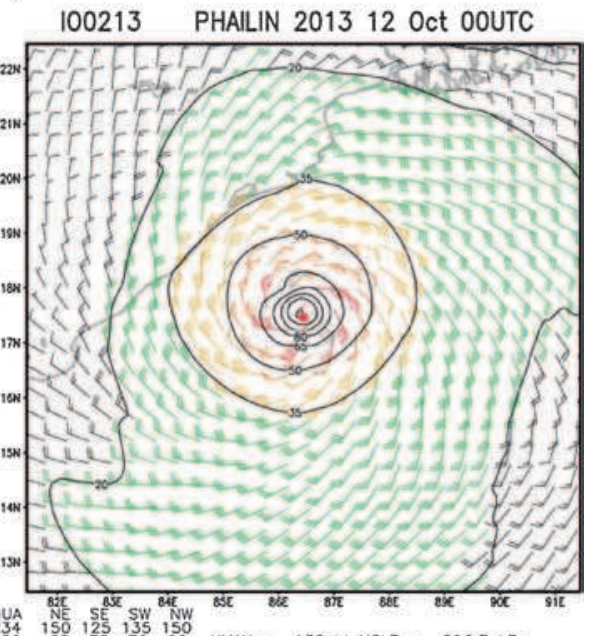

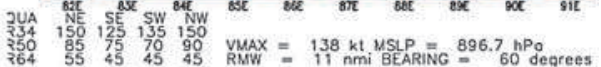

(d)

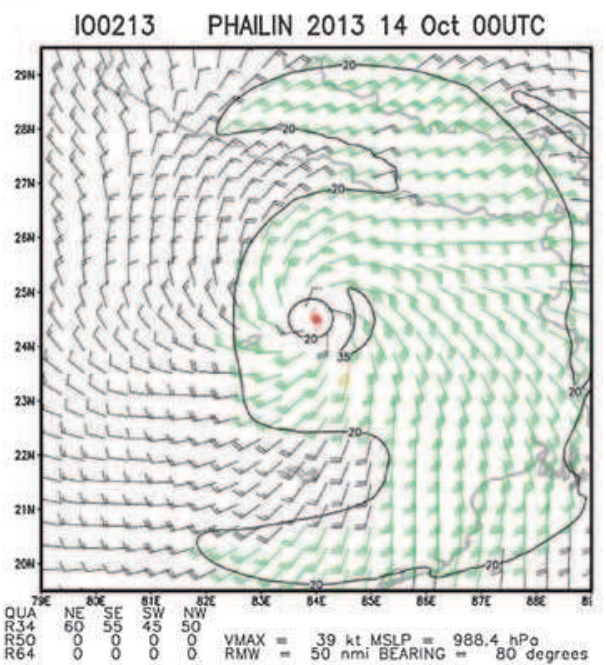

(f)

Figure 11. Surface wind distribution at (a) 1200 UTC of 9 October and (b-f) 0000 UTC of 10-14 October in association with very severe cyclonic storm, Phailin over the Bay of Bengal (8-14 October 2013). 
t) act 9 2013 12 I

Indixidual oba rhum $\%$

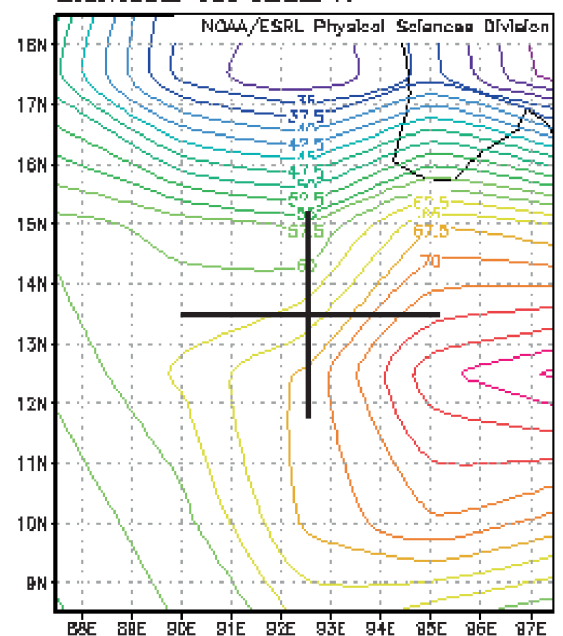

(a)

ti act $11201300 \mathrm{Z}$

Inditidual oba rhum \%

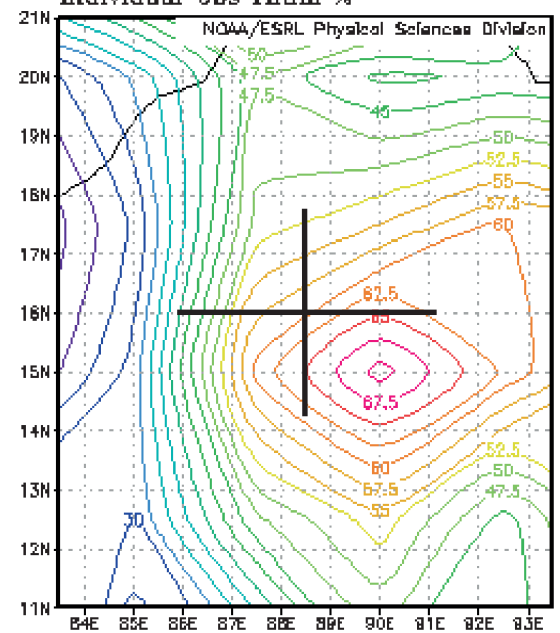

(c)

$$
\text { ti det } 13201300 Z
$$

Indiridual 0ba rhum \%

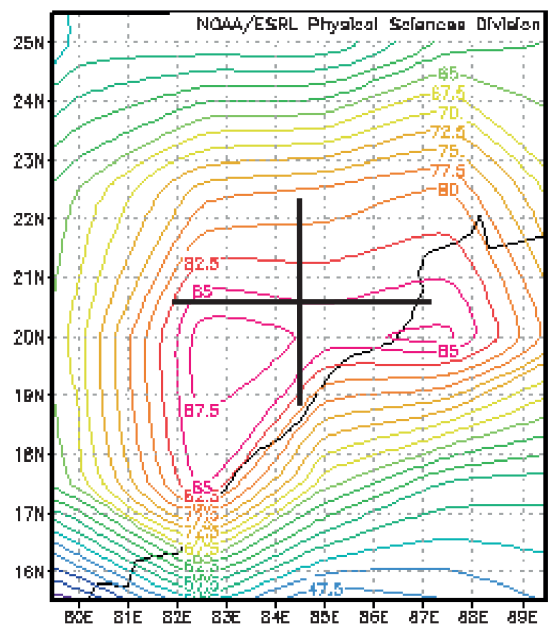

(e) t. act $10201300 \mathrm{Z}$

Individual oba rhum \%

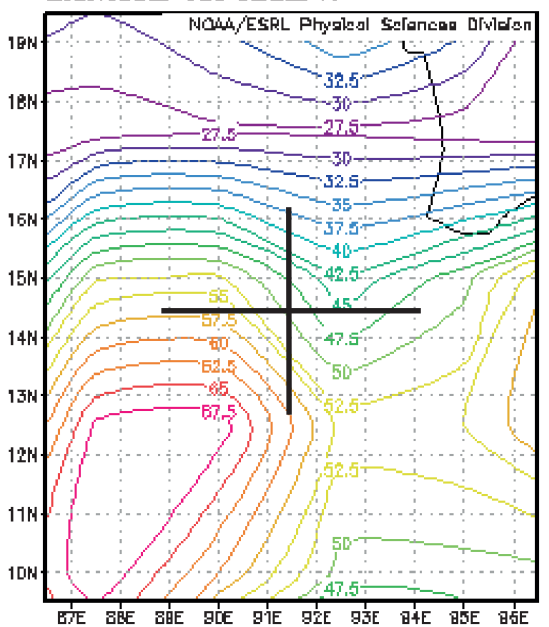

(b)

ti get $12201300 Z$

Inditidual obs rhum \%

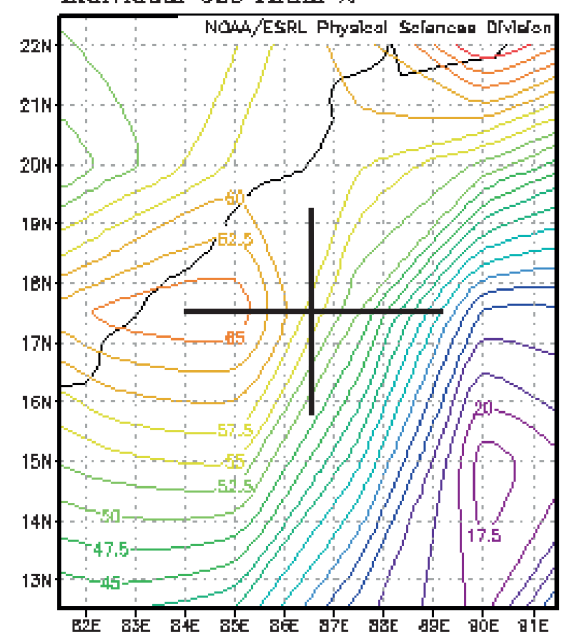

(d)

t: opet 142013007

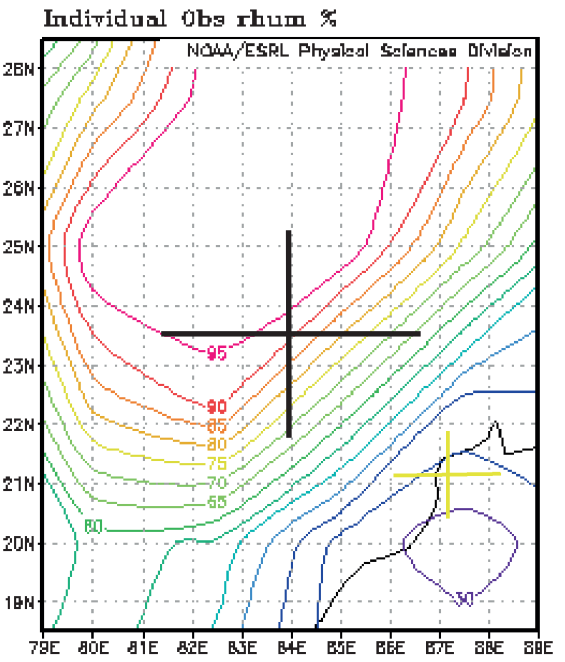

(f)

Figure 12. Relative humidity at $500 \mathrm{hPa}$ level at (a) 1200 UTC of 9 October and (b-f) 0000 UTC of 10-14 October 2013 in association with the very severe cyclonic storm, Phailin over the Bay of Bengal (8-14 October 2013). +: Centre of TC as per IMD best track. 

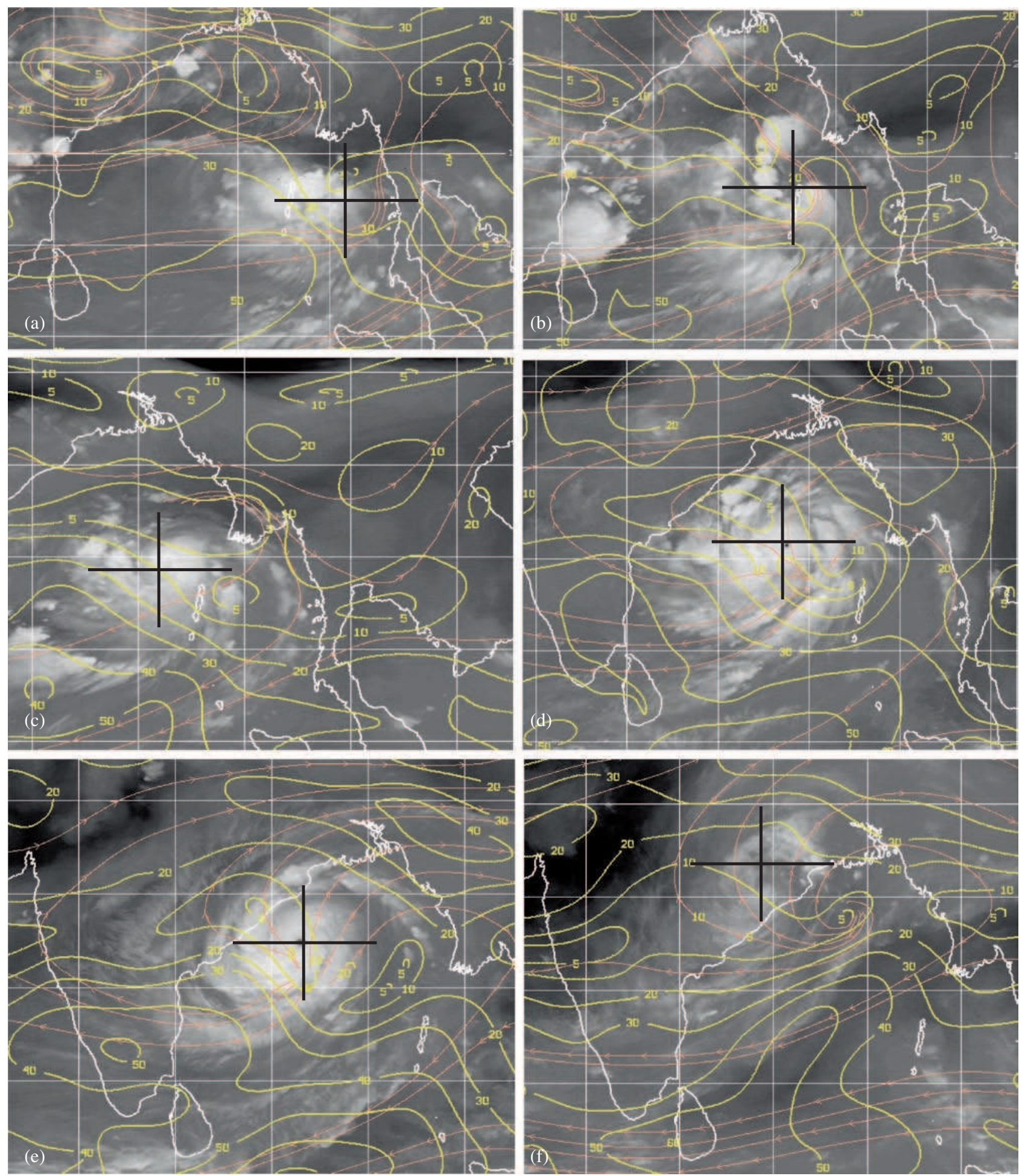

Figure 13. Vertical wind shear in a deep layer (200-850 hPa level) at (a-f) 0000 UTC of 8-13 October 2013 in association with the very severe cyclonic storm, Phailin (8-14 October 2013) over the Bay of Bengal.

(2008), when the shear amplitude is smaller than the TC motion vector, storm asymmetries tended to be on the right with respect to motion. However, under relatively strong shear conditions, that are in the same direction as motion, maximum winds could be shifted to the left with respect to motion.

\subsection{Comparison of wind radii and size of TCs over $A S$ and $B O B$ during pre- and post-monsoon seasons}

Comparing the wind radii of $34(17)$ knot $\left(\mathrm{ms}^{-1}\right)$ wind in pre- and post-monsoon season TCs over the AS (figures 2 and 6), the size of the 
Table 8. Vertical wind shear (VWS) of horizontal wind at four representative points (two degree latitude/longitude away from the centre) in four geographical quadrants of TC, Phailin.

\begin{tabular}{|c|c|c|c|c|c|c|c|c|}
\hline \multirow{2}{*}{$\begin{array}{l}\text { Date/time (UTC) } \\
\text { Quadrants } \rightarrow\end{array}$} & \multicolumn{4}{|c|}{ Magnitude of VWS knot $\left(\mathrm{ms}^{-1}\right)$} & \multicolumn{4}{|c|}{$\begin{array}{l}\text { Direction of VWS } \\
\text { according to } 16 \text { points of compass }\end{array}$} \\
\hline & $\mathrm{NE}$ & SE & SW & NW & $\mathrm{NE}$ & $\mathrm{SE}$ & SW & NW \\
\hline 08.10.13/0000 & $7(3.6)$ & $25(12.9)$ & $40(20.6)$ & $20(10.3)$ & NNE & $\mathrm{NE}$ & $\mathrm{E}$ & ENE \\
\hline 09.10.13/0000 & $15(7.7)$ & $25(12.9)$ & $30(15.4)$ & $10(5.1)$ & NW & NNE & $\mathrm{E}$ & $\mathrm{N}$ \\
\hline $10.10 .13 / 0000$ & $7(3.6)$ & $7(3.6)$ & $25(12.9)$ & $5(2.6)$ & W & $\mathrm{NE}$ & ENE & W \\
\hline $11.10 .13 / 0000$ & $18(9.3)$ & $7(3.6)$ & $25(12.9)$ & $3(1.6)$ & SW & SSW & ENE & SW \\
\hline $12.10 .13 / 0000$ & $15(7.7)$ & $10(5.1)$ & $35(18)$ & $7(3.6)$ & SSW & SSW & ENE & SSW \\
\hline $13.10 .13 / 0000$ & $30(15.5)$ & $5(2.6)$ & $10(5.1)$ & $30(15.5)$ & SSW & SSE & $\mathrm{SE}$ & SSW \\
\hline
\end{tabular}

Table 9(a). Level of significance (\%) in difference of mean wind radii of tropical cyclones over the Bay of Bengal and Arabian Sea.

\begin{tabular}{|c|c|c|c|c|c|}
\hline \multirow[b]{2}{*}{$\begin{array}{l}\text { Wind threshold } \\
\left(\mathrm{knot} / \mathrm{ms}^{-1}\right)\end{array}$} & \multirow[b]{2}{*}{ Category } & \multicolumn{4}{|c|}{ Level of significance $(\%)$ in difference of mean wind radii of TCs over BoB and AS } \\
\hline & & $\begin{array}{l}\text { AS pre-monsoon- } \\
\text { AS post-monsoon }\end{array}$ & $\begin{array}{l}\text { BOB pre-monsoon- } \\
\text { BOB post-monsoon }\end{array}$ & $\begin{array}{l}\text { AS pre-monsoon- } \\
\text { BOB pre-monsoon }\end{array}$ & $\begin{array}{l}\text { AS post-monsoon- } \\
\text { BOB post-monsoon }\end{array}$ \\
\hline \multirow[t]{4}{*}{$34 / 17$} & CS & $10 \%$ & $5 \%$ & $1 \%$ & - \\
\hline & SCS & - & - & - & - \\
\hline & VSCS & - & - & - & - \\
\hline & $\mathrm{SuCS}$ & - & - & - & - \\
\hline \multirow[t]{3}{*}{$50 / 26$} & SCS & - & - & $5 \%$ & - \\
\hline & VSCS & - & - & - & - \\
\hline & SuCS & - & - & - & - \\
\hline \multirow[t]{2}{*}{$64 / 33$} & VSCS & - & - & $5 \%$ & - \\
\hline & SuCS & - & - & - & - \\
\hline
\end{tabular}

CS: cyclonic storm, SCS: severe CS, VSCS: very severe CS, SuCS: super CS.

AS: Arabian Sea, BOB: Bay of Bengal.

- : not significant at $5 \%$ level.

Table 9(b). Level of significance (\%) in difference of mean wind radii in four geographical quadrants of tropical cyclones over the Bay of Bengal and Arabian Sea.

Level of significance (\%) in difference of mean wind radii of TCs over BoB and AS in four geographical quadrants

\begin{tabular}{|c|c|c|c|c|c|c|c|c|c|}
\hline \multirow{2}{*}{$\begin{array}{l}\text { Wind threshold } \\
\left(\mathrm{knot} / \mathrm{ms}^{-1}\right)\end{array}$} & \multirow[b]{2}{*}{ Category } & \multicolumn{4}{|c|}{ AS pre-monsoon-post-monsoon } & \multicolumn{4}{|c|}{ BOB pre-monsoon-post-monsoon } \\
\hline & & $\mathrm{NW}$ & $\mathrm{NE}$ & SW & $\mathrm{SE}$ & $\mathrm{NW}$ & $\mathrm{NE}$ & SW & $\overline{\mathrm{SE}}$ \\
\hline \multirow{3}{*}{$34 / 17$} & CS & - & - & $5 \%$ & $5 \%$ & - & $1 \%$ & - & - \\
\hline & SCS & - & - & - & - & $1 \%$ & - & - & $1 \%$ \\
\hline & VSCS & - & - & - & - & $1 \%$ & - & $5 \%$ & $5 \%$ \\
\hline \multirow[t]{2}{*}{$50 / 26$} & SCS & $5 \%$ & - & $5 \%$ & - & - & - & - & - \\
\hline & VSCS & - & - & - & - & - & - & $5 \%$ & $5 \%$ \\
\hline $64 / 33$ & VSCS & - & - & - & - & - & - & - & - \\
\hline
\end{tabular}

CS: cyclonic storm, SCS: severe CS, VSCS: very severe CS.

AS: Arabian Sea, BOB: Bay of Bengal.

-: not significant at $5 \%$ level.

CS is larger in post-monsoon at $10 \%$ level of significance (table 9a) and no difference in case of SCS or above intensity storms. The size of post-monsoon CS is almost double the size of pre-monsoon CS over AS. Comparing the wind radii in different quadrants of the TC over the AS during pre- and post-monsoon seasons (table 9b), the $34(17)$ knot $\left(\mathrm{ms}^{-1}\right)$ wind radii are higher in postmonsoon than in pre-monsoon season over SW and SE quadrants only in case of CS. It indicates dominant role played by the cross equatorial flow in enhancing the wind in SW and SE 
quadrants and minimum role of northeast monsoon circulation in the surface wind distribution for the post-monsoon TCs over the AS. When CS intensifies into SCS, there is no significant difference in $34(17)$ knot $\left(\mathrm{ms}^{-1}\right)$ wind radii in different quadrants during pre- and post-monsoon seasons. However, 50(26) knot $\left(\mathrm{ms}^{-1}\right)$ wind radii in NW and SW quadrants are significantly higher in post-monsoon than in pre-monsoon season. Thus with the intensification of $\mathrm{TC}$ over the AS, the northeast monsoon circulation as well as cross equatorial flow influence the size of core wind of the TC in NW and SW quadrants. Lee et al. (2010) examined some of the factors that control the initial size of TCs in the western-north Pacific using QuikSCAT data. Findings suggest that it is the low-level environment that determines the difference between large and small size storms during the early intensification period. Hence, similar to western-north Pacific, low level environment like enhanced cross equatorial flow leads to larger size of the TC and both cross equatorial flow and northeast monsoon circulation increase the core size of the TC over the AS in post-monsoon than in pre-monsoon season. Considering the SD (tables 2 and 5), there is large variation in the size of the CS over AS during post-monsoon than in pre-monsoon season. The SD is similar in case of SCS in both the seasons.

In comparison to the size of CSs over BOB during pre-monsoon season, the CSs in post-monsoon seasons are smaller (tables 6, 7 and 9a). The difference in mean wind radii is significant at $5 \%$ level. Considering the wind radii in different quadrants, the 34(17) knot $\left(\mathrm{ms}^{-1}\right)$ wind radii in SE quadrant of SCS and SW and SE quadrants of VSCS are higher and in NW quadrant of SCS and VSCS are less in pre-monsoon than in post-monsoon season. It may be due to enhanced cross equatorial flow over BOB during pre-monsoon season, especially in the month of June in association with the onset of summer monsoon over the region leading to higher wind in SE and SW quadrants. On the other hand, the winds are stronger in post-monsoon season over the NW quadrant in association with the northeast monsoon circulation prevalent over the BOB during this season. The size of the core wind (50(26) knot $\left(\mathrm{ms}^{-1}\right)$ wind radii) is higher in SW and SE quadrants of VSCS only during pre-monsoon than in post-monsoon season. There is no difference in $64(33)$ knot $\left(\mathrm{ms}^{-1}\right)$ wind radii in different quadrants during pre- and post-monsoon seasons. Thus, the northeast monsoon circulation has the influence only on outer core wind distribution of SCS and VSCS in NW quadrant, whereas the cross equatorial flow in association with summer monsoon influence both outer core (34(17) knot $\left.\left(\mathrm{ms}^{-1}\right)\right)$ and inner core $\left(50(26)\right.$ knot $\left.\left(\mathrm{ms}^{-1}\right)\right)$ wind distribution in SW and SE quadrants of VSCS over $\mathrm{BOB}$ during pre-monsoon season.

Comparing TCs over BOB and AS during premonsoon season, the size is significantly larger over $\mathrm{BOB}$ and the asymmetry is also higher over the BOB than over the AS (tables 3, 4, 7). Of course, the $\mathrm{SD}$ is higher over the $\mathrm{BOB}$ than over the AS indicating larger case-to-case variation over the $\mathrm{BOB}$. The significant increase in size of the TC may be due to the fact that the BOB is a smaller basin surrounded by the landmass. There is land interaction in the later part of the TC leading to increase in size of the TC. Comparing with the TCs over the AS in pre-monsoon season, the radial extents of 50(26) and 64(33) knot $\left(\mathrm{ms}^{-1}\right)$ winds are significantly less over BOB than over AS in case of SCS and VSCS respectively (tables 5 and $9 \mathrm{a}$ ). Hence, though overall size (radius of 34(17) knot $\left(\mathrm{ms}^{-1}\right)$ wind) of the TC is larger over BOB, the inner core is smaller as compared to that of the TCs over AS. In case of $64(33)$ knot $\left(\mathrm{ms}^{-1}\right)$ wind, the radius in case of $\mathrm{TC}$ over the $\mathrm{BOB}$ is almost half of that over the AS. It may be due to the fact that, the causative factor for the TCs, viz., the monsoon surge is more vigorous during onset phase of monsoon over the AS. The SDs are less and almost similar as that of TCs over the AS during pre-monsoon season. There is no significant difference in size of TCs during post-monsoon season over BOB and AS (table 9a).

\section{Conclusions}

The average size of TC (radius of 34(17) knot $\left(\mathrm{ms}^{-1}\right)$ wind) over the AS is about 43(80), 72(133), $120(222) \mathrm{nm}(\mathrm{km})$ respectively in case of CS, SCS, VSCS during pre-monsoon season and 70(130) nm $(\mathrm{km})$ in case of both CS and SCS during postmonsoon season. Similarly the average size of TC over BoB is about 73(135), 64(118) and 107(198) $\mathrm{nm}(\mathrm{km})$ in case of CS, SCS and VSCS respectively during pre-monsoon and 57(105), 64(118) and 102(189) nm (km) during post-monsoon season. The size of the SuCS, which occurred during pre-monsoon season over the AS and post-monsoon season over the BOB is about $120(222)$ and $130(241) \mathrm{nm}(\mathrm{km})$ respectively.

The size of outer core (34(17) knot $\left(\mathrm{ms}^{-1}\right)$ wind radial extension) as well as inner core winds $\left(50(26)\right.$ and $64(33)$ knot $\left(\mathrm{ms}^{-1}\right)$ wind radial extension) increases significantly with increase in intensification of $\mathrm{TC}$ over BOB during both pre- and post-monsoon seasons. Over the AS, the size of outer core of the TC increases with increase in intensity during pre-monsoon season and no significant change during post-monsoon season. 
The average sizes of outer core wind of the TCs over the BOB and AS as well as during preand post-monsoon seasons differ from each other only in case of CS stage. The average size of CS is higher in pre-monsoon than in post-monsoon season over the AS and opposite is the case over the BOB. The average size of the CS over BOB is higher than that over the AS during pre-monsoon season and there is no significant difference during post-monsoon season. Though overall size (radius of 34(17) knot $\left(\mathrm{ms}^{-1}\right)$ wind) of the TC during premonsoon season is larger over BOB, as compared to that over the AS, the inner core is smaller. In case of 64(33) knot $\left(\mathrm{ms}^{-1}\right)$ wind, the radius in case of $\mathrm{TC}$ over the BOB is almost half of that over the AS.

The outer core of winds in TCs over the BOB is asymmetric in both pre- and post-monsoon seasons and for all categories of intensity of TCs. The region of higher radial extent shifts from southern sector in CS stage to northern sector in SCS/VSCS stage of TCs over the BOB during post-monsoon season. On the other hand, the asymmetry in inner core winds is significantly less during both the seasons and all categories of intensity. There is also no asymmetry in radial wind extension over the AS during both the seasons, except in case of outer core wind radial extension of VSCS during pre-monsoon season.

The low level environment like enhanced cross equatorial flow, lower and middle level $\mathrm{RH}$, vertical wind shear and proximity of TC to the land surface are the determining factors for the size and asymmetry of TCs over the NIO.

The cross equatorial flow enhances the outer core wind (34(17) knot $\left(\mathrm{ms}^{-1}\right)$ wind radii) in SW and SE quadrants of CS only and there is minimum role of northeast monsoon circulation in the surface wind distribution for the post-monsoon TCs over the AS. However, with the intensification of TC over the AS, the northeast monsoon circulation as well as cross equatorial flow positively influence the size of core wind $\left(50(26)\right.$ knot $\left(\mathrm{ms}^{-1}\right)$ wind radii) of the TC over the AS in NW and SW quadrants.

The northeast monsoon circulation enhances only the outer core wind radii (34(17) $\operatorname{knot}\left(\mathrm{ms}^{-1}\right)$ wind radii) of SCS and VSCS in NW quadrant, whereas the cross equatorial flow in association with summer monsoon enhances both outer core (34(17) knot $\left.\left(\mathrm{ms}^{-1}\right)\right)$ and inner core $(50(26)$ knot $\left(\mathrm{ms}^{-1}\right)$ ) wind radii in SW and SE quadrants of TC over BOB during pre-monsoon season.

The asymmetry is generally higher in the sector associated with higher $\mathrm{RH}$ in lower and/or middle levels. However, there is variation in relationship between the asymmetry in surface wind and the vertical distribution of $\mathrm{RH}$ in different quadrants within the lifecycle of a TC as well as from one
TC to the other. Out of 12 cases considered for analyzing the relation between wind radii and $\mathrm{RH}$, 10 cases show definite relationship as mentioned above and other two cases (growing phase of TC, Phailin) do not show any relationship.

The quadrant with maximum outer core (34(17) knot $\left(\mathrm{ms}^{-1}\right)$ wind radii coincides with the quadrant with minimum vertical wind shear, when the TC is over the sea and not interacting with land surface. However, when the TC is over land surface and is under relatively strong shear condition, outer core wind radii are also higher in the quadrant associated with higher wind shear.

\section{Acknowledgements}

We acknowledge CIRA, USA for providing the satellite-based wind field around the TC and NCEP/NCAR for reanalysis products online which have been used in the study. We also thank Director General of Meteorology, IMD, for providing us an opportunity to carry out this work. We are thankful to the reviewers for their valuable suggestions that improved the manuscript.

\section{References}

Bessho K, DeMaria M and Knaff J A 2006 Tropical cyclone wind retrievals from the Advanced Microwave Sounder Unit (AMSU): Application to surface wind analysis; J. Appl. Meteorol. Climatol. 45 399-415.

Chourasia Manjusha, Ashrit R G and John P George 2013 Impact of cyclone bogusing and regional assimilation on tropical cyclone, track and intensity predictions; Mausam 64 135-148.

Colon Jose A, Raman C R V and Srinivasan V 1970 Tropical cyclone of May 1963 over Arabian Sea; Indian J. Meteorol. Geophys. 21 1-22.

Dean L, Emanuel K A and Chavas D R 2009 On the size distribution of Atlantic tropical cyclones; Geophys. Res. Lett. 36 L14803, doi: 10.1029/2009GL039051.

Demuth J L, DeMaria M, Knaff J A and Vonder Haar T H 2004 Evaluation of advanced microwave sounding unit tropical-cyclone intensity and size estimation algorithms; J. Appl. Meteorol. 43 282-296.

Demuth J L, DeMaria M and Knaff J A 2006 Improvement of advanced microwave sounding unit tropical cyclone intensity and size estimation algorithms; J. Appl. Meteorol. Climatol. 45 1573-1581.

Dube S K, Jisme Poulose and Rao A D 2013 Numerical simulation of storm surge associated with severe cyclonic storm in the Bay of Bengal during 2008-2011; Mausam 64 193-202.

Frank William M 1977 The structure and energetics of the tropical cyclone II. Dynamics and energetics; Mon. Wea. Rev. 105 1136-1150.

Fujibe F and Kitabatake N 2007 Classification of surface wind fields of tropical cyclones at landfall on the Japan main islands; J. Meteor. Soc. Japan 85 747-765.

Goldberg M D 1999 Generation of retrieval products from AMSU-A: Methodology and validation; 10th International TOVS Study Conference, Boulder, Colorado, 27 January-2 February. 
Hill K A and Lackmann G M 2009 Influence of enviromental humidity on tropical cyclone size; Mon. Wea. Rev. 10 3294-3315.

IMD 2008 Tracks of cyclones and depressions (1891-2007), electronic version 1.0/2008; IMD, Chennai, India.

IMD 2013 Cyclone warning in India: Standard operation procedure; Published by IMD, New Delhi, India.

Jarvinen B R, Neuman C J and Davis M A S 1988 A tropical cyclone data tape for the north Atlantic basin; NOAA Tech. Memo. NWS NHC-22, 21p.

Kanamitsu M, Ebisuzaki W, Woollen J, Yang S-K, Hnilo J J, Fiorino M and Potter G L 2002 NCEP-DOE AMIPII Reanalysis (R-2); Bull. Am. Meteorol. Soc. 83 1631-1643.

Knaff J A, DeMaria M, Molenar D A, Sampson C R and Seybold M G 2011 An automated, objective, multisatellite platform tropical cyclone surface wind analysis; J. Appl. Meteorol. 50 2149-2166.

Knaff J A, Sampson C R, DeMaria M, Marchok T P, Gross J M and McAdie C J 2007 Statistical tropical cyclone wind radii prediction using climatology and persistence; Wea. Forecasting 22 781-791.

Kossin J P, Knaff J A, Berger H I, Herndon D C, Cram T A, Velden C S, Murnane R J and Hawkins J D 2007 Estimating hurricane wind structure in the absence of aircraft reconnaissance; Wea. Forecasting 22 89-101.

Koteswaram P and Gaspar S 1956 The surface structure of tropical cyclone in the Indian Ocean; Indian J. Meteorol. Geophys. 7 339-352.

Lee C-S, Cheung K K W, Fang W-T and Elsberry R L 2010 Initial maintenance of tropical cyclone size in the western north Pacific; Mon. Wea. Rev. 138 3207-3223.
Maclay K S, DeMaria M and Vonder Haar T H 2008 Tropical cyclone inner core kinetic energy evolution; Mon. Wea. Rev. 136 4882-4898.

Mohapatra M, Bandyopadhyay B K and Tyagi Ajit 2012 Best track parameters of tropical cyclones over the north Indian Ocean: A review; Natural Hazards 63 1285-1317.

Mueller K J, DeMaria M, Knaff J A, Kossin J P and Vonder Haar T H 2006 Objective estimation of tropical cyclone wind structure from infrared satellite data; Wea. Forecasting 21 990-1005.

Rappaport E N and Co-authors 2009 Advances and challenges at the National Hurricane Center; Wea. Forecasting 24 395-419.

Rao Y P 1976 "Southwest Monsoon." Meteorol. Monogr. Synoptic Meteorol., No. 1/1976, India Meteorological Department, New Delhi, 335p.

RSMC, New Delhi 2011 Report on cyclonic disturbances over the north Indian Ocean during 2010; IMD, New Delhi, India.

Uhlhorn E W and Black P G 2003 Verification of remotely sensed sea surface winds in hurricanes; J. Atmos. Oceanic. Technol. 20 99-116.

Uhlhorn E W, Franklin J L, Goodberlet M, Carsell J and Goldstein A S 2007 Hurricane surface wind measurement from operational stepped frequency microwave radiometer; Mon Wea. Rev. 135 1370-1385.

Ueno M 2008 Effects of ambient vertical wind shear on the inner-core asymmetries and vertical tilt of a simulated tropical cyclone; J. Meteor. Soc. Japan 86 531-555.

$\mathrm{Xu}$ Jing and Wang Y 2010 Sensitivity of tropical cyclone inner-core size and intensity to the radial distribution of surface entropy flux; J. Atmos. Sci. 67 1831-1852. 